\title{
Article \\ Comparative Study of Tribomechanical Properties of HiPIMS with Positive Pulses DLC Coatings on Different Tools Steels
}

\author{
Adrián Claver ${ }^{1, *}$, Emilio Jiménez-Piqué ${ }^{2,3}$, José F. Palacio ${ }^{4}$, Eluxka Almandoz ${ }^{4}$, Jonathan Fernández de Ara ${ }^{4} \mathbb{D}_{\text {, }}$ \\ Iván Fernández ${ }^{5}$, José A. Santiago ${ }^{5}$, Eneko Barba ${ }^{6}$ and José A. García ${ }^{1,7}$ (D) \\ 1 Engineering Department, Public University of Navarre (UPNA), Campus Arrosadía S/N, \\ 31006 Pamplona, Spain; joseantonio.garcia@unavarra.es \\ 2 Department of Material Science and Engineering, Universitat Politécnia de Catalunya \\ (UPC-Barcelona TECH), Campus Diagonal Besòs, 08019 Barcelona, Spain; emilio.jimenez@upc.edu \\ 3 Barcelona Research Center in Multiscale Science and Engineering, UPC-Barcelona TECH, \\ Campus Diagonal Besòs, 08019 Barcelona, Spain \\ 4 Centre of Advanced Surface Engineering, AIN, 31191 Cordovilla, Spain; jfpalacio@ain.es (J.F.P.); \\ ealmandoz@ain.es (E.A.); jfernandez@ain.es (J.F.d.A.) \\ 5 Nano4Energy SL, José Gutiérrez Abascal 2, 28006 Madrid, Spain; ivan.fernandez@nano4energy.eu (I.F.); \\ joseantonio.santiago@nano4energy.eu (J.A.S.) \\ 6 Nuadi Components S.L., Polígono Ind. Arazuri-Orcoyen, Calle D, 2, 31170 Arazuri, Spain; \\ Eneko.Barba@nuadi.com \\ 7 Institute for Advanced Materials (INAMAT), Public University of Navarre, Campus Arrosadía S/N, \\ 31006 Pamplona, Spain \\ * Correspondence: adrian.claver@unavarra.es; Tel.: +34-676-927-082
}

\section{check for}

updates

Citation: Claver, A.; Jiménez-Piqué, E.; Palacio, J.F.; Almandoz, E.; Fernández de Ara, J.; Fernández, I.; Santiago, J.A.; Barba, E.; García, J.A. Comparative Study of Tribomechanical Properties of HiPIMS with Positive Pulses DLC Coatings on Different Tools Steels. Coatings 2021, 11, 28. https://doi.org/10.3390/ coatings 11010028

Received: 17 November 2020 Accepted: 22 December 2020 Published: 29 December 2020

Publisher's Note: MDPI stays neutral with regard to jurisdictional clai$\mathrm{ms}$ in published maps and institutional affiliations.

Copyright: (C) 2020 by the authors. Licensee MDPI, Basel, Switzerland. This article is an open access article distributed under the terms and conditions of the Creative Commons Attribution (CC BY) license (https:// creativecommons.org/licenses/by/ $4.0 /)$.

\begin{abstract}
Diamond-like carbon (DLC) coatings are very interesting due to their extraordinary properties; their excellent wear resistance, very low friction coefficient, great hardness, high elastic modulus or biocompatibility can be highlighted, as can their multifunctionality. Because of this, over recent decades they have been widely used in tribological applications, improving the performance and the useful life of machining tools in an effective way. However, these coatings have a disadvantage compared to other coatings deposited by commercially available techniques-their resultant adhesion is worse than that of other techniques and limits their industrial applications. In this work, tribological results of a scratch test, wear resistance and nanoindentation of tetrahedral amorphous carbon (ta-C) and tungsten carbide:carbon (WC:C) DLC coatings deposited by means of novel highpower impulse magnetron sputtering (HiPIMS) technology with positive pulses are reported. The coatings were deposited in three different tools steels: K360, vanadis 4 and vancron. These tools steels are very interesting because of their great and wide industrial applicability. Experimental results showed excellent tribological properties, such as resistance to wear or adhesion, in the two types of DLC coatings.
\end{abstract}

Keywords: HiPIMS; positive pulse; DLC coatings; tribology; adhesion; wear resistance

\section{Introduction}

Diamond-like carbon (DLC) coatings are considered as one of the most promising and valuable industrial materials due to their applicability in a large number of applications thanks to their great properties - their combination of high hardness, low friction, high wear resistance and chemical inertness [1-3]. These properties can be attributed to the fact that DLCs are a metastable form of amorphous carbon that combines the structure of diamond and graphite with an amorphous network of carbon atoms in covalent $\mathrm{sp}^{2}$ and $\mathrm{sp}^{3}$ bond hybridization $[4,5]$. Therefore, the properties will very much depend on the relation between the amount of $\mathrm{sp}^{2}$ and $\mathrm{sp}^{3}$ bonds. The tribological properties of DLC coatings, such as low friction and resistance to abrasive and adhesive wear, are particularly good under conditions of low humidity, and the smoothness of the film would also be an 
important parameter in sliding wear applications [6]. These properties combined with a high load resistance and excellent sliding properties make these coatings an ideal option for tribological applications [7]. It should also be noted that, as shown in reference [7], in friction tests, a higher friction force must be applied for converting static friction into dynamic friction when DLC coatings are used. Because of this, it can be said that there are well-known and consolidated surface treatments that can be applied to different types of substrates, with metals and ceramics standing out $[5,8]$. Among their main applications, their use in improving the tribological properties of cutting and forming tools $[9,10]$, or molds for injection of plastics, can be highlighted [11], providing these items with a high protection against abrasive wear. Other industrial sectors where it is common to use these coatings would be medical devices [12], automotive components [13] and electronics and optics applications [14], among others.

However, DLC coatings have a disadvantage in comparison to other coatings deposited by different deposition techniques that prevents their wider use in industry $[15,16]$. They show a low adhesion to the substrate due to the low density of chemical bonds derived from poor surface preparation, differences in the type of chemical bonding in the coating/substrate interface [17] and the residual stresses generated during the deposition process. For instance, in coated steel tools, premature adhesive failures or delamination can occur due to this problem [18].

Despite showing a poor adhesion to the substrate, DLC coatings are gaining a lot of importance in the field of surface engineering-i.e., they have increased their share in the global market from USD $800 \mathrm{M}$ to around USD 1.7 billion in the last decade and their revenue has been increasing with a compound annual growth rate of approximately $14 \%$ over the past 5 years [19]. They are gaining especial importance in the development of solutions to improve the performance of cutting and forming tools $[8,9,20]$ by improving their properties and durability and, hence, increasing the productivity of manufacturing processes [21].

DLC coatings can be deposited using different techniques, such as PVD (Physical vapor deposition) cathodic arc, PVD magnetron sputtering or PACVD (Plasma Assisted Chemical Vapor Deposition). In the synthesis of metal-containing DLC coatings, conventional magnetron sputtering techniques have been more frequently used than the rest; however, due to the fairly low degree of ionization of metal and gas species, often lowdensity microstructures and poor mechanical properties are obtained [22,23]. Furthermore, these coatings are deposited with an interlayer to promote their adhesion to the substrate and to ensure a better chemical compatibility between the steel and the coating [24]. However, this improved adherence may not be enough when high loads are applied, leading to coating detachments [25]. For this reason, new techniques that sought to achieve coatings with great adhesion while maintaining the excellent mechanical and tribological properties were developed. Some recent studies showed improvements in adherence, with values of second critical scratch load (Lc2) being $25 \mathrm{~N}$ [26] or around $10 \mathrm{~N}$ [27], although these values are insufficient for the applications mentioned above. Other works tried to improve the adhesion by applying duplex treatments on different types of steel, which consists of a previous thermochemical plasma nitriding pretreatment followed by a DLC deposition $[28,29]$. The problem with this solution is that the pretreatment could impair the corrosion resistance of the substrate [30]. In reference [31], Lc2 values close to $40 \mathrm{~N}$ were shown in multilayered DLC-PAPVD coatings on standard and triode plasma nitrided substrates. Some authors have shown an improvement in the adhesion by using multilayered coatings combining a filtered cathodic vacuum arc and high-power impulse magnetron sputtering (HiPIMS), accommodating the growth morphology and internal stress by means of stepwise decreasing bias [32].

The use of the novel HiPIMS technique has been reported elsewhere [23,33,34]. In the first study [23], the effect of different positive voltage amplitudes on the discharge process and the mechanical properties of the deposited DLC hard coatings were studied, but no information about the resulting adherence is reported. The works $[33,34]$ achieved 
an increase in the resultant adhesion and in the wear resistance of two different types of DLC coatings, such as tetrahedral amorphous carbon (ta-C) and tungsten carbide:carbon (WC:C), using the novel high-power impulse magnetron sputtering (HiPIMS) method that incorporates positive voltage pulses after the conventional HiPIMS discharge, and that were deposited on high speed steel substrates and 1.2379 tool steel, respectively.

The objective of this work is to evaluate the tribological and mechanical properties of two DLC coatings - tetrahedral amorphous carbon (ta-C) and tungsten carbide:carbon (WC:C) — deposited by HiPIMS with positive pulses on three different tool steels for industrial applications (K360, vanadis 4 and vancron), with the aim of improving the adhesion of the coatings. This technique improves on the conventional HiPIMS in terms of adherence. In this work, this increase in adherence has been studied, and it has been verified on different substrates, which are tool steels with great industrial applicability that are subjected to great efforts.

\section{Materials and Methods}

\subsection{Reference Substrate}

Samples of brand-specific steels-Uddeholm vanadis 4, BÖHLER K360 ISODUR and Uddeholm vancron - with flat geometries and $30 \mathrm{~mm}$ diameters were used as reference substrates. Before the plasma treatment, all the specimens were polished and cleaned. The polishing process was performed to achieve a final Ra value less than 0.2 microns. Afterwards, a thorough cleaning process was performed, which consisted of the sequence of operations shown below: ultrasonic washing with alkaline detergents (1\% Tickopurr R33), rinsing with deionized water, cleaning with isopropanol and air-drying, respectively. The chemical compositions of the materials are shown in Table 1.

Table 1. Chemical composition of the 3 tools' steels studied in this work (wt.\%).

\begin{tabular}{cccccccc}
\hline Steel & C (\%) & Si (\%) & Cr (\%) & N (\%) & V (\%) & Mn (\%) & Mo (\%) \\
\hline K360 & 1.25 & 0.9 & 8.75 & - & 1.18 & 0.35 & 2.7 \\
Vanadis 4 & 1.4 & 0.4 & 4.7 & - & 3.7 & 0.4 & 3.5 \\
Vancron & 1.3 & 1.8 & 4.5 & 1.8 & 10 & - & - \\
\hline
\end{tabular}

These steels have been chosen due to their extraordinary mechanical properties and their high industrial applicability, where cold work tool applications, such as cutting, stamping or extrusion tools, stand out. In these applications, the tools were subjected to great repetitive stress; therefore, the materials must be hard and resistant to compression, must have enough toughness to withstand the working conditions to which they are subjected to and they must have high wear resistance [35]. In this way, it will be possible to increase their useful life and increase productivity [36]. In addition, it should be noted that the strength of commercial metal alloys is increasing, which requires harder, stronger and more durable tool steels for their forming or cutting [37]. The hardness of tool steels is typical of quenching martensite and is influenced by the carbides deposited in the martensitic matrix [36]. These carbides are very hard substances present in the steel in the form of inclusions and can be transformed into other harder carbides by adding elements such as chromium, molybdenum, vanadium, tungsten, titanium, etc. [36]. The amount, shape, size and nature of these carbides will affect the hardness as well as wear resistance [38-41]. The 3 steels selected for this study meet these requirements and are of a higher quality than conventional steels, but vanadis 4 and vancron steels are of a higher quality than K360. Although all 3 have good dimensional stability and a finer carbide distribution, vanadis 4 and vancron are powder metallurgical steels, while K360 is an Electroslag remelting (ESR) steel. The dimensional stability and homogeneity of carbides is superior in the case of powder metallurgical steels; in addition, they present a higher metallurgical purity and are free of segregations, which makes their qualities superior [42-47]. The properties presented by the 3 steels, such as dimensional stability or high toughness, make them ideal for PVD treatments. 


\subsection{Film Deposition Technique}

The system that the depositions were carried out on is the industrial system $\times P r o 4 C$, designed by PVT GmbH (Bensheim, Germany). It has a vacuum chamber of $0.51 \mathrm{~m}^{3}$ $(680 \mathrm{~mm} \times 650 \mathrm{~mm} \times 1150 \mathrm{~mm})$ where it integrates four cathodes designed with adjustable magnetic field configurations. A scheme of this can be seen in Figure 1.

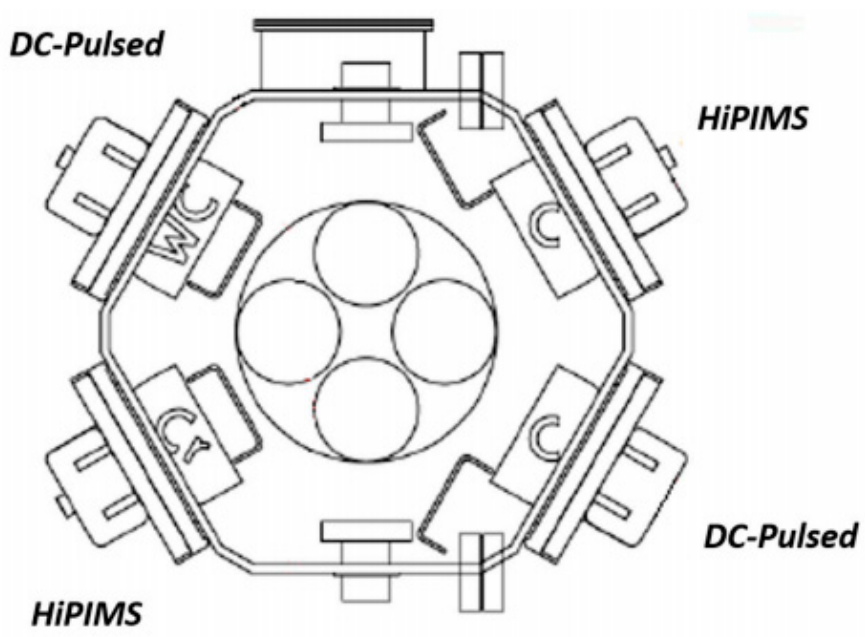

Figure 1. Cross-section of the process chamber.

In the chamber, a base pressure of $10^{-6}$ mbar was achieved thanks to the use of two turbomolecular pumps and two double-stage rotary vane pumps. The four cathodes were incorporated in equidistance. Two of them carried graphite targets. For DLC coating deposition, the first of them was operated under the unbalanced magnetron mode (UBM) and the other one under the HiPIMS V+ mode. The third cathode carried a binder-free WC target and was used for depositing a WC interlayer with a balanced magnetron configuration. The last one mounted a $\mathrm{Cr}$ target and was operated in the HiPIMS mode.

Before depositing the coatings, it is necessary to carry out a pretreatment on the substrate. The sequence of parameters used in this process and during deposition are described below:

- Ar etching: a direct current (DC)-pulsed bias voltage of $-500 \mathrm{~V}$ and a frequency of $150 \mathrm{kHz}$ was used to establish an Ar+ discharge at the substrate for $15 \mathrm{~min}$;

- Cr-HiPIMS deposition of a bonding layer: the target was operated in HiPIMS mode with a pulsing time of $150 \mu \mathrm{s}$, repetition frequency of $300 \mathrm{~Hz}$ and an average power density of $5 \mathrm{~W} / \mathrm{cm}^{2}$. The voltage bias of the substrate was adjusted from -750 to $-50 \mathrm{~V}$, and a deposition rate of $0.5 \mu \mathrm{m} / \mathrm{h}$ was obtained for a three-fold rotation at a substrate voltage bias of $-50 \mathrm{~V}$;

- Deposition of the WC interlayer: DC-pulsed mode with the following parameters was used to deposit WC-a power density of $7.5 \mathrm{~W} / \mathrm{cm}^{2}$, a frequency rate of $150 \mathrm{kHz}$ and a pulse width of $2.7 \mu \mathrm{s}$. Moreover, the substrate was biased at $-50 \mathrm{~V}$. The deposition rate obtained in this way for a three-fold rotation was $0.38 \mu \mathrm{m} / \mathrm{h}$;

- (A) Deposition of the ta-C coatings: the pulses applied to the graphite target reached power densities of up to $10 \mathrm{~W} / \mathrm{cm}^{2}$. During ta-C deposition, both $C$ targets are used at the same time. One of them operated in DC-pulsed mode and the other in HiPIMS mode. A repetition frequency of $150 \mathrm{kHz}$ and a pulse width of $2.4 \mu$ s were used to apply the DC-pulsed mode. The operation parameters of the HiPIMS mode were a pulsing time of $150 \mu \mathrm{s}$, repetition frequency of $300 \mathrm{~Hz}$ and a positive pulse of $350 \mathrm{~V}$. A substrate voltage bias of $-50 \mathrm{~V}$ was applied, and the deposition rate obtained for a three-fold rotation was $0.25 \mu \mathrm{m} / \mathrm{h}$;

- (B) Deposition of WC:C coatings: the graphite targets were operated under the same conditions mentioned in 4 a. WC was codeposited with carbon at $0.75 \mathrm{~W} / \mathrm{cm}^{2}$, a 
frequency rate of $150 \mathrm{kHz}$ and a pulse width of $2.7 \mu \mathrm{s}$. The deposition rate obtained for a three-fold rotation was $0.3 \mu \mathrm{m} / \mathrm{h}$.

\subsection{Thickness, Structural Properties and Profile Composition}

Glow discharge optical emission spectrometry (GD-OES) was used to analyze the chemical composition profiles and the resultant thicknesses of the coatings. The employed equipment was a JOBIN YVON 100000RF GD-OES equipment (HORIBA Instruments, Kyoto, Japan) [48]. With the aim of confirming the previous results in terms of thickness, it was also measured by means of a CSM Calotest equipment (CSM Instruments, Needham, MA, USA) using a $30 \mathrm{~mm}$ diameter stainless-steel ball and superfine $(0.25 \mu \mathrm{m})$ diamond water suspension as the abrasive medium.

The structural properties of DLC films were evaluated using Raman spectroscopy. A Renishaw spectrometer was used to record the Raman spectra, focusing a green ion laser with a line of $532 \mathrm{~nm}$ on the surface of the coatings with a power of $100 \mathrm{~mW}$. The obtained Raman spectrum was curve-fitted using two Gaussian functions, peaking at disordered (D-band) and graphite (G-band) modes. In addition, the ratio of peak heights was used in order to obtain the relative intensity ratio of the $\mathrm{D}$ and $\mathrm{G}$ bands (ID/IG).

Finally, in order to obtain information about the layers, cross-section images were obtained by a FEI Verios 460 Field Emission XHR-SEM microscope (FEI, Hillsboro, OR, USA).

\subsection{Mechanical and Tribological Tests}

The adhesion assessment between the substrate and coatings was carried out with a CSM REVETEST Scratch tester fitted with a diamond Rockwell indenter (EURO 150518 $C \& N)$ with a tip radius of $200 \mu \mathrm{m}$. The test parameters that were used were a load rate of $100 \mathrm{~N} / \mathrm{min}$, a final load of $100 \mathrm{~N}$, a speed of $9.58 \mathrm{~mm} / \mathrm{min}$ and a total test length of $10 \mathrm{~mm}$.

During the adhesion tests, different signals (penetration of the indenter within the substrate, acoustic emission, coefficient of friction) were recorded and the spots where the different events occurred were observed by optical microscopy. Using all this information, three different critical loads (LC) were registered:

- The first critical load (LC1): the first cohesive failure observed;

- The second critical load (LC2): the first adhesive failure appreciated;

- The third critical load (LC3): a total delamination of the coating or even a critical defect is clearly observed in the reference substrate.

In the scratch tests, a progressive load is applied through the indenter on the surface of the samples, and while this load increases, different failure modes will appear. First, failure mechanisms, such as plastic deformation, fissurations for conformal type, fissurations of tensile or lateral fissurations, will be observed that are related to failure mechanisms of the cohesive type (Lc1). After this, failure mechanisms such as delaminations, fissurations by frontal deformation, superficial lifts or lateral chipping, among others, will appear, which are related to failure mechanisms of the adhesive type (Lc2). Finally, the applied load will be high enough to remove more than half of the coating from the substrate (Lc3).

A Microtest MT series equipment (Microtest S.A.) was used for the tribomechanical tests. Pin-on-disk tests were performed using $6 \mathrm{~mm}$ alumina balls, each of which had a surface maximum roughness of $\mathrm{Ra}_{\max }=0.050 \mu \mathrm{m}$ and hardness of around $1650 \mathrm{HV}$, as the pins, and the different samples of coated and uncoated tools steels as the disks. The tests were carried out at a $40 \mathrm{~N}$ load, $200 \mathrm{rpm}$ and 20,000 cycles, which supposes a Hertzian contact stress of $2.6 \mathrm{GPa}$. Tests were repeated three times at 8,10 and $12 \mathrm{~mm}$ (track radii). As these are high performance tool steels and coatings with very good tribological properties, it was necessary to use a high load at enough revolutions to generate a measurable and homogeneous wear track. These conditions are more similar to the real cases of application of these coatings, such as cold stamping or forming applications, where high pressures are applied. Other studies have used similar parameters with this type of coatings [34]. The corresponding wear tracks have been measured by using a Confocal S mart Microscope (Sensofar) and an optical microscope. The volume loss as well as the wear evaluation 
were determined in two ways: according to ASTM G99 [49] and straight from the confocal measures of volume loss.

Nanohardness measurements were performed with an MTS NANOINDENTER XP fitted with a Berkovich tip, a maximum depth of $2000 \mathrm{~nm}$ and a maximum load of $25 \mathrm{mN}$. Hardness and Young's modulus values were obtained by the Oliver and Pharr method [50] with the influence of the substrate in the hardness and Young's modulus corrected using Bec et al.'s thin film model [51,52].

\section{Results}

\subsection{Thickness, Structural Properties and Profile Composition}

The calotest measurements that were carried out to determine the resultant thickness of the coating can be seen in Figure 2. The measurements of the calotest show several circumferences (marked in Figure 2 in red, yellow and orange) corresponding to different depth levels, caused by rolling the ball with abrasives during the test. The relationship between these dimensions allows the determination of the thickness of the coating. The results showed that the samples coated with ta-C have thicknesses of just about $1.65 \mu \mathrm{m}$; the samples coated with WC:C, instead, showed thicknesses of approximately $2 \mu \mathrm{m}$. These results are consistent with those obtained in the glow discharge optical emission spectrometry (GD-OES), shown in Figure 3.
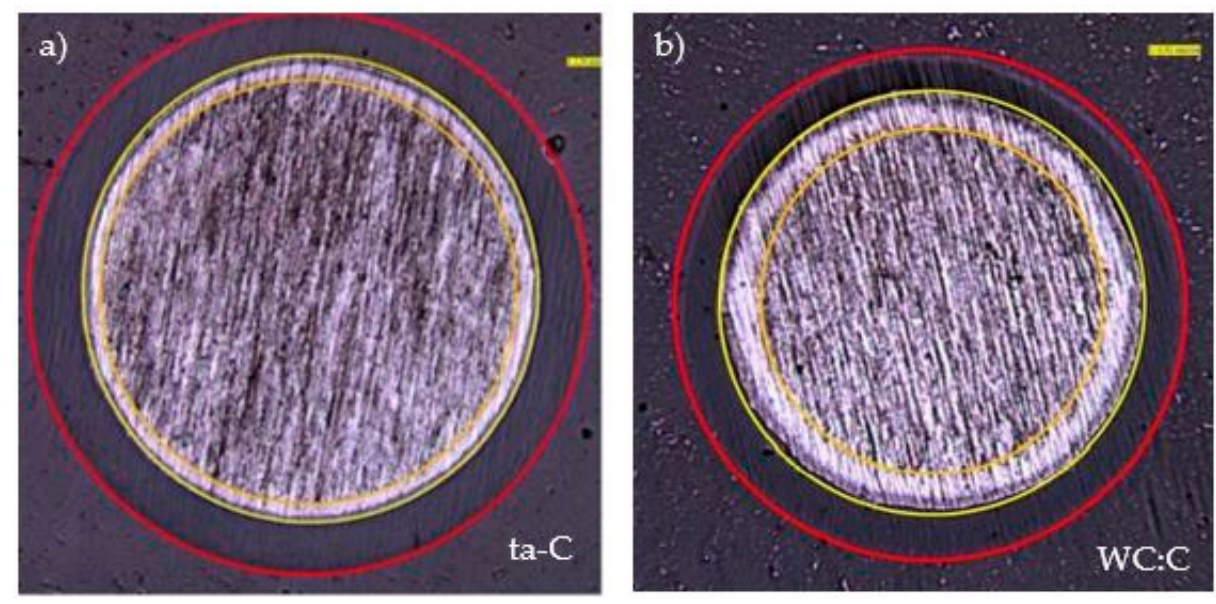

Figure 2. Calotest craters used to determine the resultant thickness for the tetrahedral amorphous carbon (ta-C) coated sample (a) and tungsten carbide:carbon (WC:C) coated sample (b). The different circumferences correspond to the different rings exposed after the abrasion of the coating with the balls used for the calculation of the different thicknesses.

Following with the GD-OES, the ta-C layer showed an approximate thickness of $1.5 \mu \mathrm{m}$. The weight percentage concentration in $\mathrm{C}$ was higher than $90 \%$ during the first $0.65 \mu \mathrm{m}$, followed by a WC layer of about $0.85 \mu \mathrm{m}$ where the weight content of carbon decreased across the layer. An anchoring layer of $0.2 \mu \mathrm{m}$ in chromium can also been observed, which has the aim of improving the adhesion to the substrate. On the other hand, the WC:C coating showed a thickness of around $1.75 \mu \mathrm{m}$ composed by two different layers. For the first $0.75 \mu \mathrm{m}$ in depth, a top carbon layer doped with $\mathrm{W}$ can be seen, containing $60 \% \mathrm{C}$ and $40 \% \mathrm{~W}$ in weight. This layer is followed by a transition layer of about $1 \mu \mathrm{m}$ in thickness than contains mainly $\mathrm{W}$ with the content of $\mathrm{C}$ decreasing across the layer from $60 \%$ in weight to less than $5 \%$. As in the previous case, a chromium-anchoring layer of approximately $0.3 \mu \mathrm{m}$ can also been observed before reaching the reference substrate. 
a)

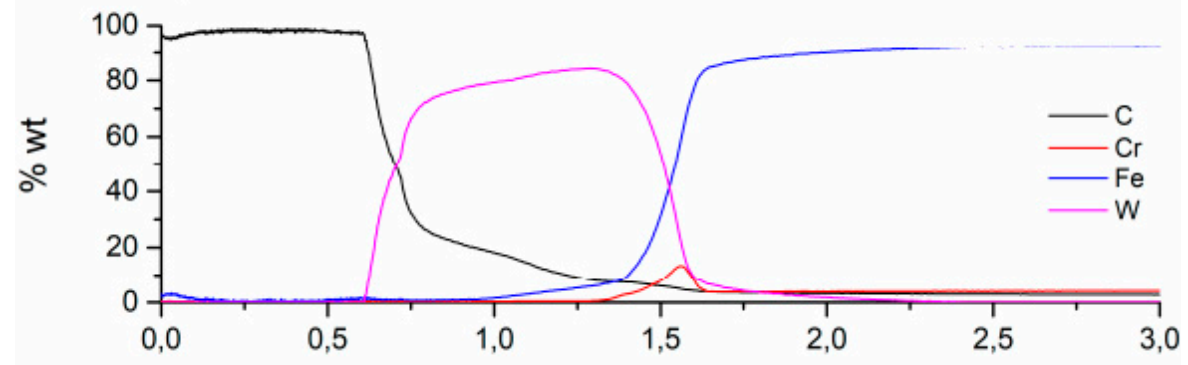

b)

Depth $(\mu \mathrm{m})$

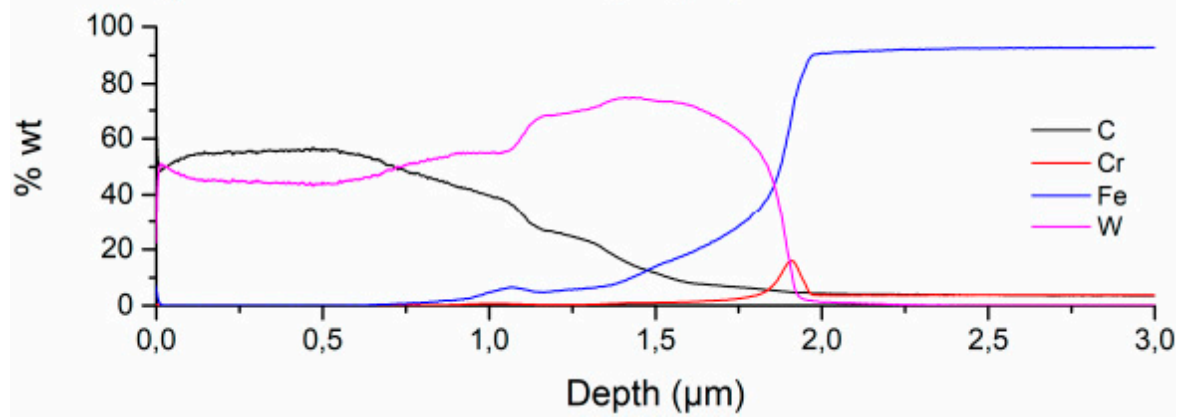

Figure 3. Glow discharge optical emission spectrometry (GD-OES) concentration profiles in the sample of ta-C coating (a) and WC:C coating (b).

Figure 4 shows the cross-section SEM picture of the coatings, where the different layers are schematically indicated. From bottom to top:

- HSS substrate;

- $\mathrm{Cr}$ bonding layer is not visible due to low resolution for observing $10 \mathrm{~nm}$ of thickness;

- WC interlayer;

- DLC coating;

- Pt coating. There is a double layer of Pt coating on top. As the coating has been milled with FIB (focused ion beam) for cross-sectional (XS) observation, a Pt layer has been deposited on top in order to prevent the etching of the DLC coating due to ion irradiation.

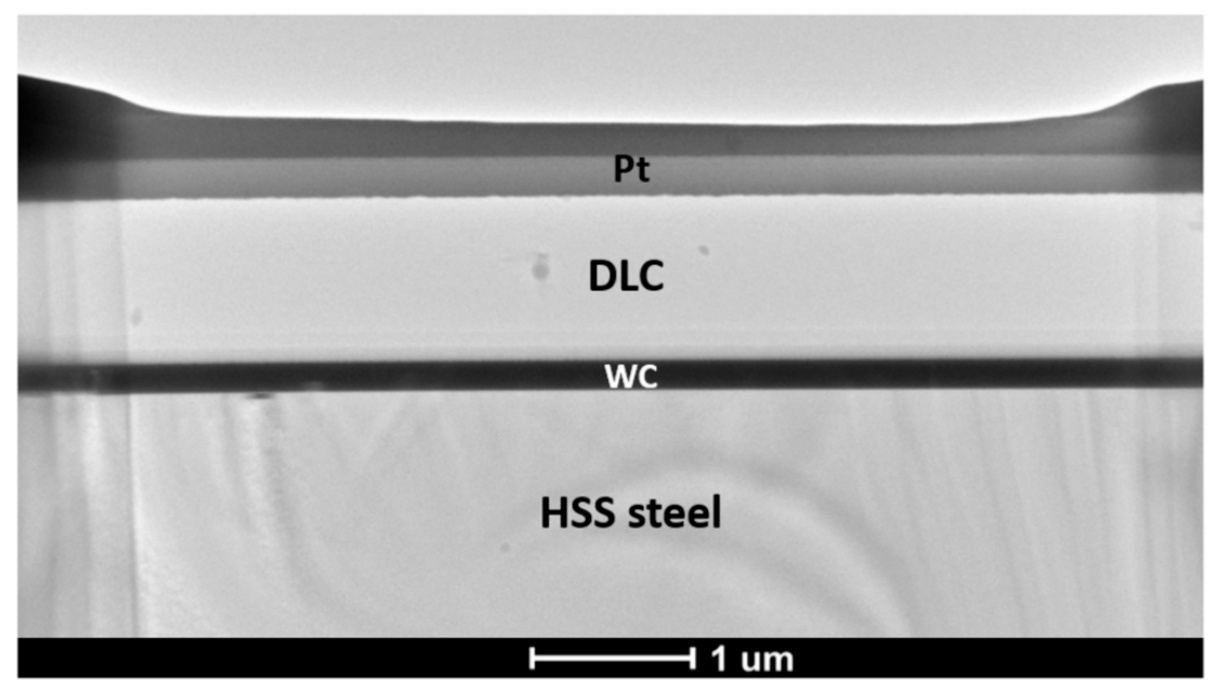

Figure 4. Cross-section SEM picture with the coating's structure. 
Raman characterization was performed in order to evaluate the structural properties of DLC films. Raman spectra were recorded using a Renishaw's inVia Qontor Raman microscope (Renishaw, Gloucestershire, UK). A green ion laser with a line of $532 \mathrm{~nm}$ was focused on the surface of the coatings with a power of $100 \mathrm{~mW}$. The obtained Raman spectrum was curve-fitted using two Gaussian functions, peaking at disordered (D-band) and graphite (G-band) modes.

It is important to note that amorphous tetrahedral carbon (ta-C) structures have higher contents of $\mathrm{sp}^{3}$ bonds than amorphous carbon structures. The $\mathrm{I}(\mathrm{D}) / \mathrm{I}(\mathrm{G})$ ratio, which is shown in the Table 2, normally correlates with the $\mathrm{sp}^{2} / \mathrm{sp}^{3}$ fraction, so it was evaluated to check if the above statement is fulfilled. Therefore, it is expected that those structures that present a higher content of $\mathrm{sp}^{2}$ enhancements have a higher value for the $\mathrm{I}(\mathrm{D}) / \mathrm{I}(\mathrm{G})$ ratio [53]. In the samples analyzed, the highest value for this relationship was obtained for the K360 with WC:C case (with a value of 0.93 ), followed by the vanadis 4 with WC:C and vancron with WC:C samples (0.91). This means that these samples are the ones with the highest number of graphitic layers with $\mathrm{sp}^{2}$ bonds. On the other hand, for the K360, vancron and vanadis 4 with ta-C samples, the values obtained were $0.74,0.71$ and 0.69 , respectively.

Table 2. Summary of the experimental data derived from the Raman spectroscopy.

\begin{tabular}{cccccc}
\hline Substrate and Coating & $\mathbf{G}\left(\mathbf{c m}^{-\mathbf{1}}\right)$ & $\mathbf{I}(\mathbf{G})$ & $\mathbf{D}\left(\mathbf{c m}^{-\mathbf{1}}\right)$ & $\mathbf{I}(\mathbf{D})$ & I (D)/I (G) \\
\hline K360 WC:C & 1.573 & 5.704 & 1.360 & 5.3137 & 0.93 \\
K360 ta-C & 1.527 & 12.192 & 1.326 & 9.058 & 0.74 \\
Vanadis 4 ta-C & 1.521 & 13.058 & 1.326 & 9.058 & 0.69 \\
Vanadis 4 WC:C & 1.568 & 9.240 & 1.381 & 8.4057 & 0.91 \\
Vancron WC:C & 1.560 & 8.155 & 1.383 & 7.446 & 0.91 \\
Vancron ta-C & 1.536 & 6.206 & 1.328 & 4.429 & 0.71 \\
\hline
\end{tabular}

The presence of a D peak is consistent with the spectrum of aromatic hydrocarbons. Therefore, if a clear D peak is observed, it will be because of the ring's breathing modes. However, on the contrary, not observing a D peak will mean that there is an absence of rings [53]. In the samples analyzed, in those coated with ta-C, peak $D$ is less defined. Therefore, it can be assumed that they have fewer aromatic rings. Peaks G and D can be seen in Figure 5.

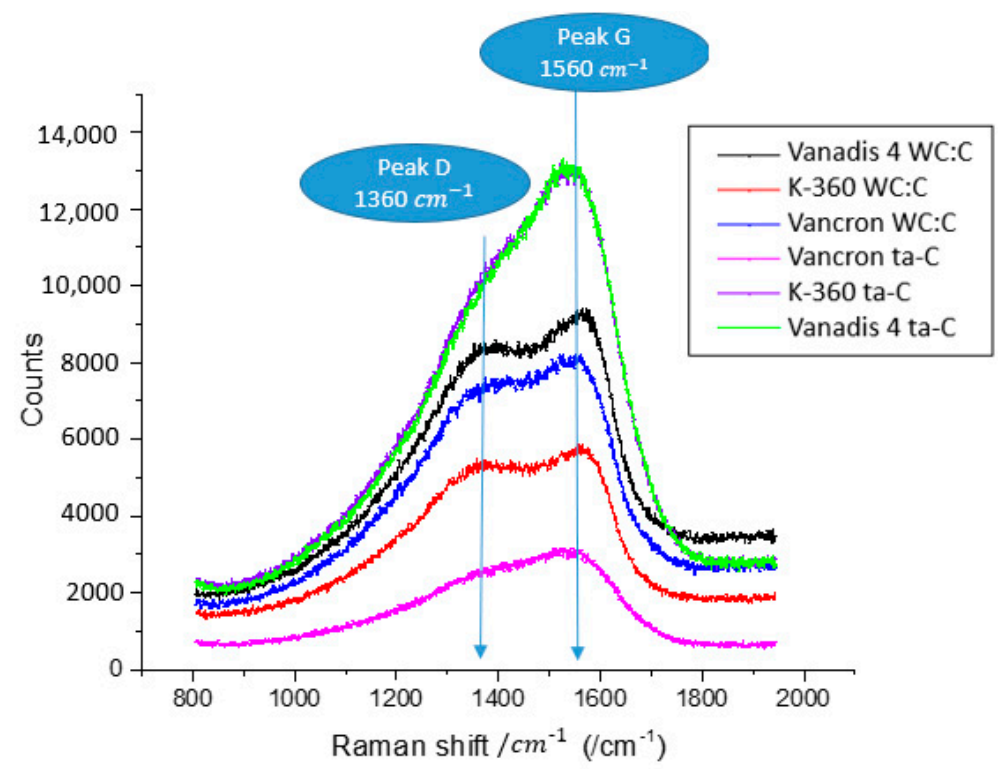

Figure 5. Raman spectra of all the coated samples. 
In turn, as previously mentioned, the $\mathrm{sp}^{3}$ concentration, the existence of a D peak, and therefore of aromatic rings, are related to the mechanical properties of the samples. Consequently, it could be assumed that those films that present a lower concentration of clustering achieve higher hardness.

\subsection{Nanoindentation Tests}

Figure 6 represents the nanoindentation tests up to a final load of $25 \mathrm{mN}$. As can be seen in the results, a specific hardness of $24 \mathrm{GPa}$ was obtained for the ta-C coated K360 layer and $14 \mathrm{GPa}$ for the WC:C coated one. In the case of the vanadis 4 layers, a specific hardness of $26 \mathrm{GPa}$ was obtained for the ta-C coated layer, whereas a hardness of $14 \mathrm{GPa}$ was reached for the WC:C layer.

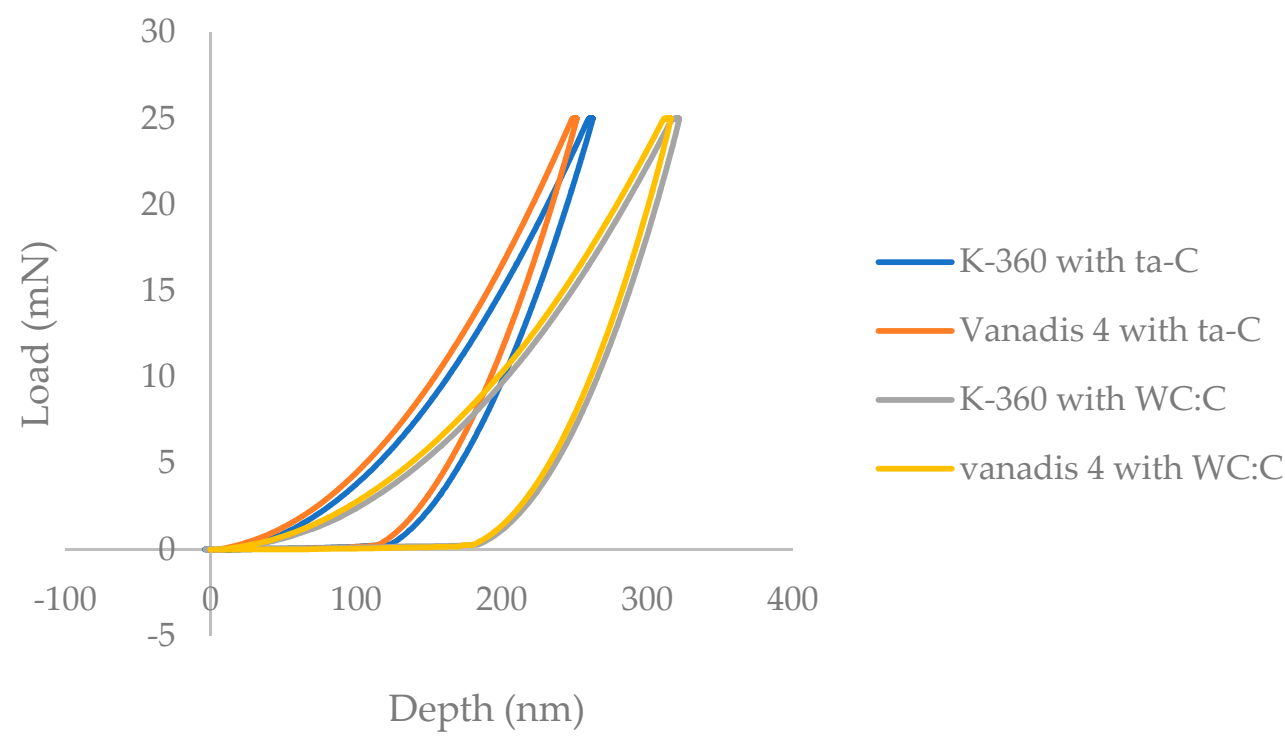

Figure 6. Nanoindentation curves for a specific final load of $25 \mathrm{mN}$ in the $\mathrm{K} 360$ with ta-C coating (blue plot), vanadis 4 with ta-C coating (orange plot), K360 with WC:C coating (grey plot) and vanadis 4 with WC:C coating (yellow plot).

The results of nanoindentation are similar to those reported by García et al. [34], showing values of 17 GPa for the WC:C coating and 30 GPa for ta-C. Duminica et al. [27] and Czyzniewski [54] also presented similar hardness values-between 21 and 23 GPa and $19 \mathrm{GPa}$, respectively.

In the load-displacement curves, a high elastic component can be observed for both type of coatings. The final depth was significantly greater for the WC:C coatings compared to the ta- $C$ coatings. The corresponding hardness values, the Young modulus values and the relationship between hardness and modulus $\left(\mathrm{H}^{3} / \mathrm{E}^{2}\right)$ are shown in Table 3. The value of $\mathrm{H}^{3} / \mathrm{E}^{2}$ is not very high in the coatings and it is especially low in the case of WC:C. Higher values were reported in other studies: García et al. [34] showed values of 0.15 for WC:C coatings and 0.45 for ta-C coatings, while Sun et al. [55] presented values between 0.243 and 0.263 . The $\mathrm{H}^{3} / \mathrm{E}^{2}$ and $\mathrm{H} / \mathrm{E}$ ratios, which relate the hardness and the Young modulus, are considered as indicators of resistance to plastic deformation in loaded contact and the elasticity index [56,57], respectively. Due to this, they are used to determine the toughness and the wear resistance of the coatings $[56,58]$ since it is generally accepted that it is possible to adjust the wear resistance of a solid by adapting its elastoplastic properties, which could be summarized by increasing the hardness or decreasing the elastic modulus [59]. $\mathrm{H}^{3} / \mathrm{E}^{2}$ is related to the elastic limit of the material; therefore, it is expected that an increase in $\mathrm{H}^{3} / \mathrm{E}^{2}$ will lead to an improvement in the elastic recovery of the coating (a highly elastic behavior of the film under contact events), which is also related to the toughness $[57,60,61]$. It should be noted that, different studies conclude that parameters such as $\mathrm{H} / \mathrm{E}$ and $\mathrm{H}^{3} / \mathrm{E}^{2}$ are more important than just hardness in determining the good wear resistance of a material and 
they highlight the importance of toughness in various tribological applications [56-58,62]. Theoretical analyses and research works have analyzed the relation between the parameter $\mathrm{H}^{3} / \mathrm{E}^{2}$ and the wear resistance, and they have proved that resistance to various forms of wear is correlated with the ratio $\mathrm{H}^{3} / \mathrm{E}^{2}[54,55,57,63]$. Finally, it should be added that different investigations reported that the value of $\mathrm{H}^{3} / \mathrm{E}^{2}$ is related with the grain size of the nanostructure, so that the smallest grain size and highest fraction of phase boundaries lead to higher values of $\mathrm{H}^{3} / \mathrm{E}^{2}[57,58,64]$. According to this, it can be said that the resistance to plastic deformation of the ta-C coating is higher than that of WC:C, and that, therefore, the wear resistance of ta-C should also be higher than that of WC:C.

Table 3. Summary of the experimental data derived from the nanoindentation curves such as the resultant hardness $(\mathrm{H})$, Young modulus (E) and the $\mathrm{H}^{3} / \mathrm{E}^{2}$ relationship, respectively.

\begin{tabular}{ccccc}
\hline Substrate & DLC Coating & Hardness $(G P a)$ & Young Modulus (GPa) & H $^{3} / \mathbf{E}^{2}$ \\
\hline K360 & ta-C & $24 \pm 3$ & $311 \pm 27$ & 0.148 \\
K360 & WC:C & $14 \pm 1$ & $257 \pm 22$ & 0.043 \\
Vanadis 4 & ta-C & $26 \pm 2$ & $343 \pm 30$ & 0.152 \\
Vanadis 4 & WC:C & $15 \pm 2$ & $277 \pm 27$ & 0.041 \\
\hline
\end{tabular}

\subsection{Adhesion Tests}

Scratch tests were performed on all the DLC coated specimens to evaluate their mechanical response and adhesion to the substrate. Figure 7 shows an example of the results obtained for the case of specimens with vanadis 4 as substrate (Figure 7a for the WC:C coating and Figure $7 \mathrm{~b}$ for the ta-C coating); similar results were obtained in all cases. The acoustic emission (AE\%) and the coefficient of friction (COF) establish a relationship between the normal and tangential forces, respectively, and they are represented in these figures. From these tests, the different failure modes along the scratches were evaluated and the critical loads at which they occurred were recorded. With the experimental results, it was possible to study the differences between the properties of the different coatings and substrates, with the objective of evaluating which one presents better adherence.

The results obtained from these adhesion tests were very positive for both coatings, even though clear differences were found between them. Table 4 summarizes the results of the three critical loads (Lc1, Lc2 and Lc3) recorded for each specimen. The samples coated with WC:C presented the first cohesive failure (Lc1) at about $19 \mathrm{~N}$. The first adhesive failure (Lc2), instead, appeared at around $59 \mathrm{~N}$ in the vanadis 4 and vancron samples and at $32.9 \mathrm{~N}$ in the K360 sample, while the appearance of the substrate (Lc3) occurred at around $77 \mathrm{~N}$ in the vanadis 4 and vancron samples and a little bit earlier in the K360 sample-at $73.8 \mathrm{~N}$. Looking at the Lc2 results, it is clear that the adhesion of the K360 steel is slightly worse than the other two steels with this coating. On the other hand, no cohesive failure was observed in any of the three ta-C coated samples; however, the results of Lc2 and Lc3 show that their adhesion was worse than the ones coated with WC:C. In these specimens, Lc2 was defined at about $25 \mathrm{~N}$, whereas the Lc3 appeared at around $50 \mathrm{~N}$ in the K360 and vancron samples and at $40.3 \mathrm{~N}$ in the vanadis 4 sample. The addition of $\mathrm{W}$ to the DLC structure allows one to reduce compressive residual stress, as reported in [65]. A reduction in residual stress allows one to enhance adhesion critical load values despite showing lower values of hardness and wear resistance. As can be seen in Table 5, the adhesion results obtained in this study are higher than those reported in the references $[26,27,66]$. On the other hand, similar results of Lc2 were reported in reference [34], with ta-C and WC:C coatings, or in reference [67], showing Lc2 values up to $42 \mathrm{~N}$ to W-doped DLCs. 


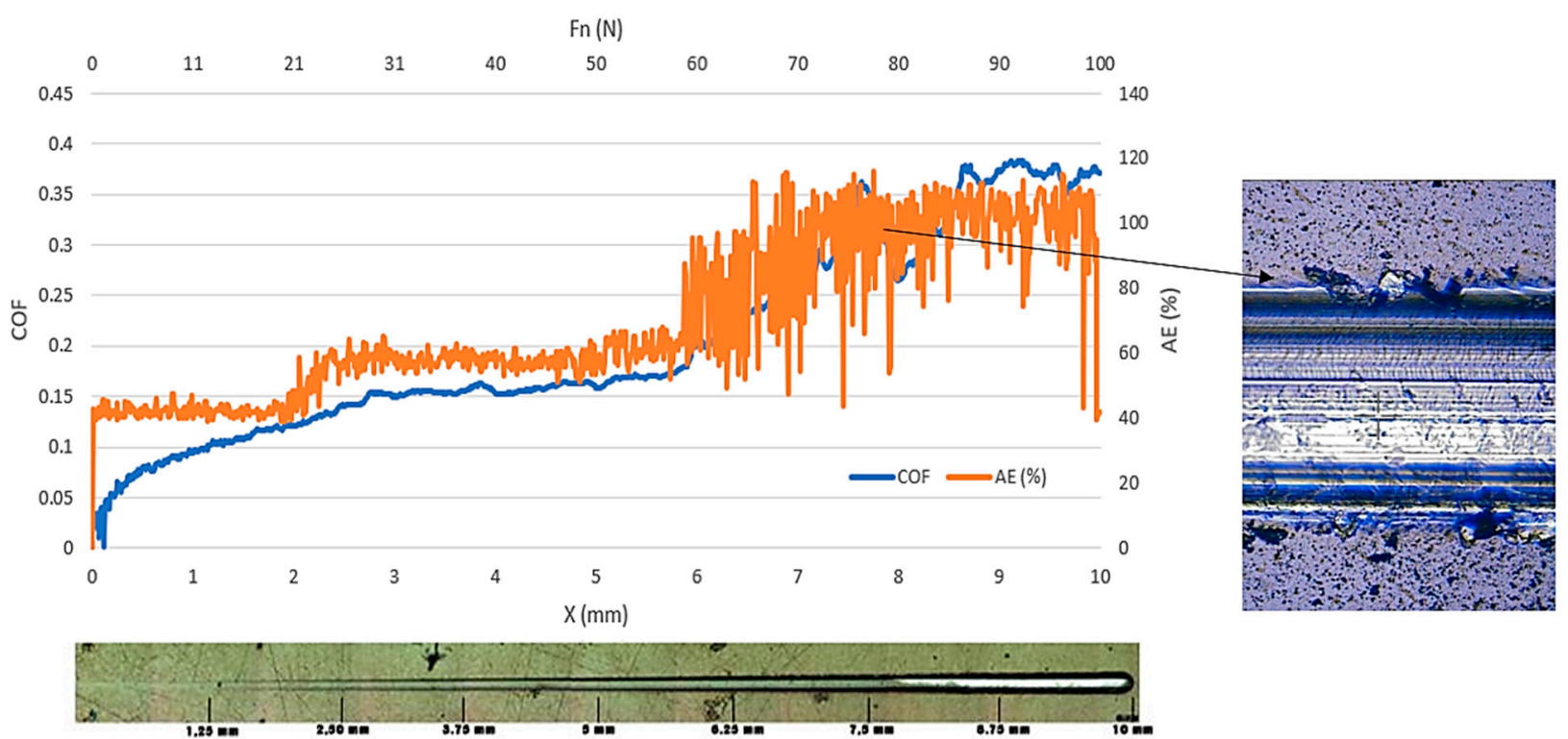

(a)
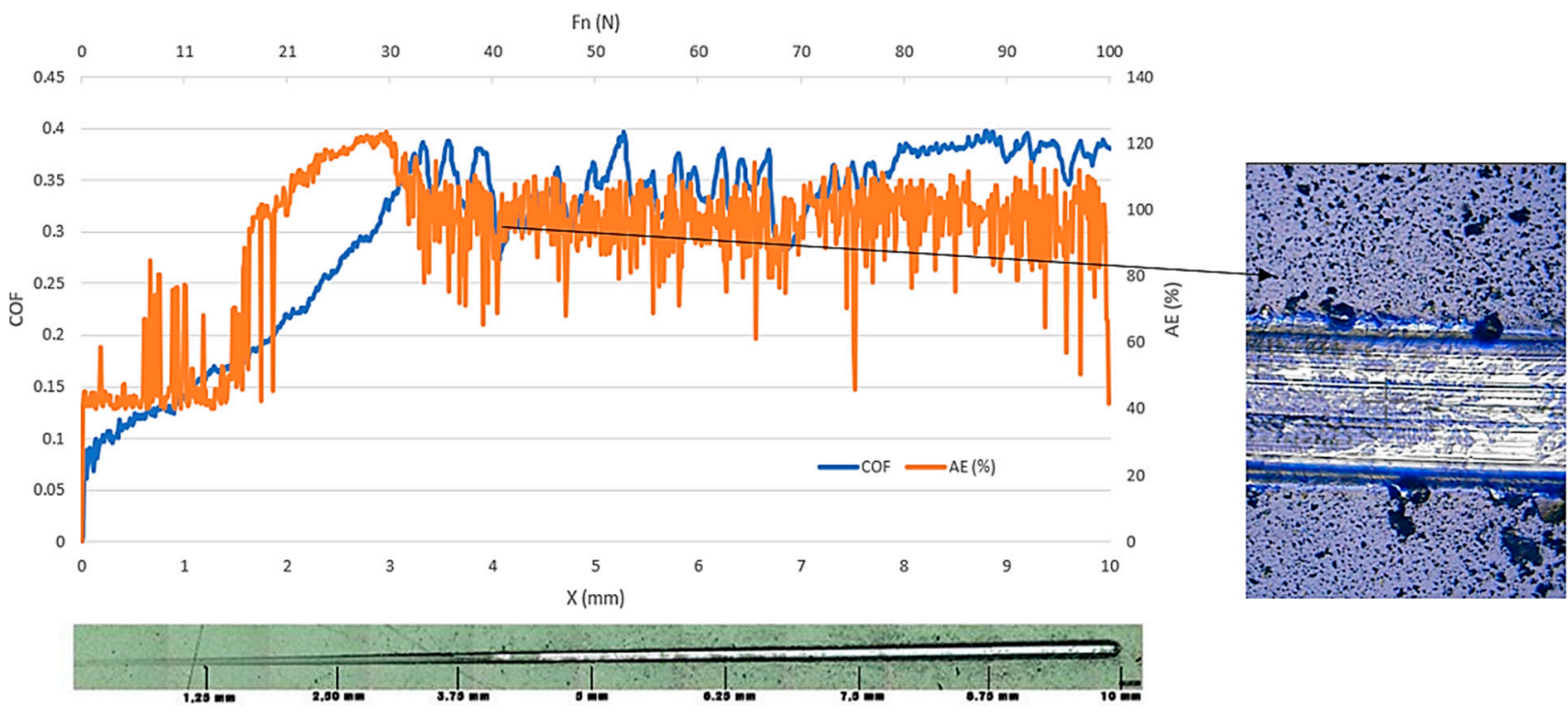

(b)

Figure 7. Example of the scratch test results. Evolution of the coefficient of friction (blue plot) and acoustic emission (orange plot) vs. the indenter displacement and the normal force: WC:C coated vanadis 4 sample (a) and ta-C coated vanadis 4 sample (b).

Table 4. Summary of the critical load values obtained for each sample from the scratch test.

\begin{tabular}{cccc}
\hline Substrate and Coating & Lc1 (N) & Lc2 (N) & Lc3 (N) \\
\hline K360 WC:C & $18.9 \pm 0.7$ & $32.9 \pm 0.6$ & $73.8 \pm 4.0$ \\
Vanadis 4 WC:C & $19.2 \pm 0.4$ & $58.8 \pm 1.3$ & $77.6 \pm 2.3$ \\
Vancron WC:C & $19.0 \pm 2.1$ & $59.8 \pm 0.7$ & $77.1 \pm 3.9$ \\
K360 ta-C & - & $29.6 \pm 2.5$ & $50.7 \pm 3.7$ \\
Vanadis 4 ta-C & - & $25.0 \pm 3.1$ & $40.3 \pm 1.1$ \\
Vancron ta-C & - & $24.4 \pm 4.2$ & $50.4 \pm 5.4$ \\
\hline
\end{tabular}


Table 5. Summary of the critical load Lc2 values obtained for each reference from the scratch test.

\begin{tabular}{cccc}
\hline Reference & Coating & Deposition Technique & Lc2 (N) \\
\hline$[26]$ & DLC & Nitrided substrate + HiPIMS & 25 \\
{$[27]$} & Cr(N)/DLC multilayer & DC magnetron sputtering & 10 \\
{$[34]$} & ta-C & HiPIMS with positive pulses & 18.86 \\
{$[34]$} & WC:C & HiPIMS with positive pulses & 40.87 \\
{$[66]$} & DLC & Plasma-enhanced chemical & 12 \\
{$[67]$} & W-doped DLC & vapordeposition (PECVD) & 42 \\
\hline
\end{tabular}

\subsection{Friction and Wear Tests}

A pin-on-disc tribometer was used to study the friction and wear properties of the DLC coatings as well as those of the reference substrates. The experimental results are shown in Figure 8. The coefficients of friction (COFs) are $0.7-0.8$ for the uncoated samples. However, all the samples coated with ta-C showed a COF of around 0.07 which is lower than that shown by the samples coated with WC:C, which was around 0.1 . The fluctuations in the COF curves during the run-in period are inherent to the test itself; during steady state, instead, they are related to the apparition of different tribo-oxidation bodies. Depending on test conditions, during the run-in period, it the formation of oxide phases in W-doped DLC coatings has been observed, which could lead to a higher COF before the formation of more lubricious graphitic tribolayers, as reported by [68]. This is the reason for obtaining higher friction in run-in period for the WC:C coatings than for the ta- $\mathrm{C}$ coating. The COF results are lower than those reported by Wang et al. [69], where values of COF between 0.12 and 0.21 for WC-DLC coatings are reported, or in reference [70], where values of $0.12-0.59$ for DLC coatings on AISI H11 steels with plasma nitriding pretreatment are reported. However, similar results are reported in references [26,71].

Comparing the width of the wear tracks, it can be seen how clearly the wear has been greater for the uncoated samples. As shown in Figure 9, the width of the wear track measured in the uncoated samples takes values around 500-800 $\mu \mathrm{m}$ for the vancron and vanadis 4 samples and 1500-2000 $\mu \mathrm{m}$ for the case of the K360 specimen. The coated specimens, instead, present values close to $350 \mu \mathrm{m}$ for the case of the WC:C coatings and $200 \mu \mathrm{m}$ for those of ta-C. In all cases, the highest values were obtained for the K360 samples. From the images obtained by optical and confocal microscopy shown in Figure 9 the type of wear shown by each specimen can also be determined. Clear differences were observed between the type of wear for each coated sample. In the ta-C coated samples, very little abrasive wear was observed on the surface, while in the WC:C coated samples, typical microscratches were found. Despite the differences, it is clear that both coatings improve the wear resistance of the substrates-calculations made to determine the volume loss and wear coefficient will be shown in the paper and will show consistency with this statement.

The evaluation of the volume loss and the wear coefficient were carried out using two different methods. The first method consists of using the measurement of the width of the wear track and determining the values of volume loss and wear coefficient following what the ASTM G99 standard establishes. The standard determines the value of the volume loss for the entire track using the measured value of the wear track width. This result is then used to calculate the wear coefficient through a formula that relates it to the applied load in the test and the total sliding distance, thus obtaining a normalized value for the wear coefficient. The second method, however, consists of calculating the volume loss directly using the confocal microscope and the Sensoview program, and then extrapolating that value for the entire wear track using the equation shown in formula (1). Then, the wear coefficient value is calculated using the same equation as in the first method.

$$
\frac{\mathrm{V} \text { loss confocal }\left(\mathrm{m}^{3}\right)}{\text { wear track length }(\mathrm{m})} \times 2 \times \Pi \times \mathrm{r}(\mathrm{m})=\mathrm{V} \text { loss }\left(\mathrm{m}^{3}\right)
$$


VANADIS-4

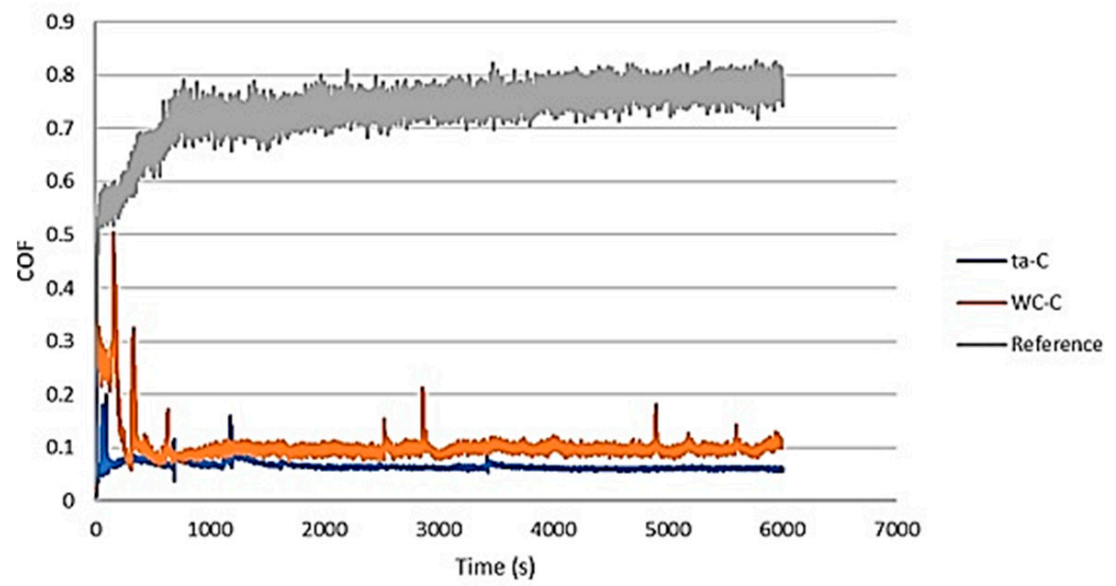

(a)

K-360

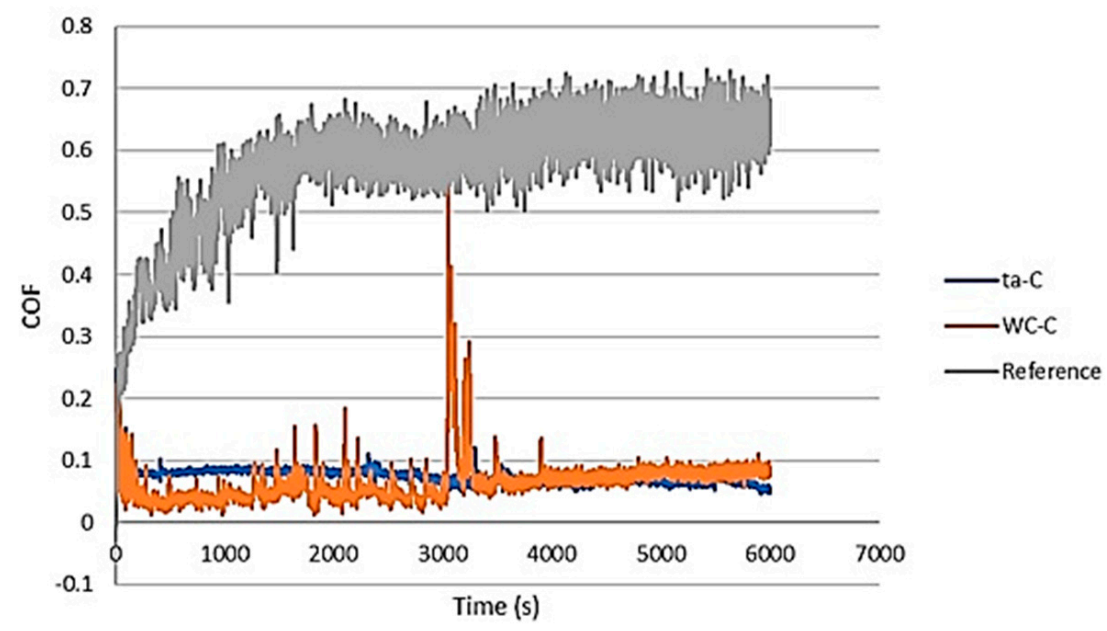

(b)

VANCRON

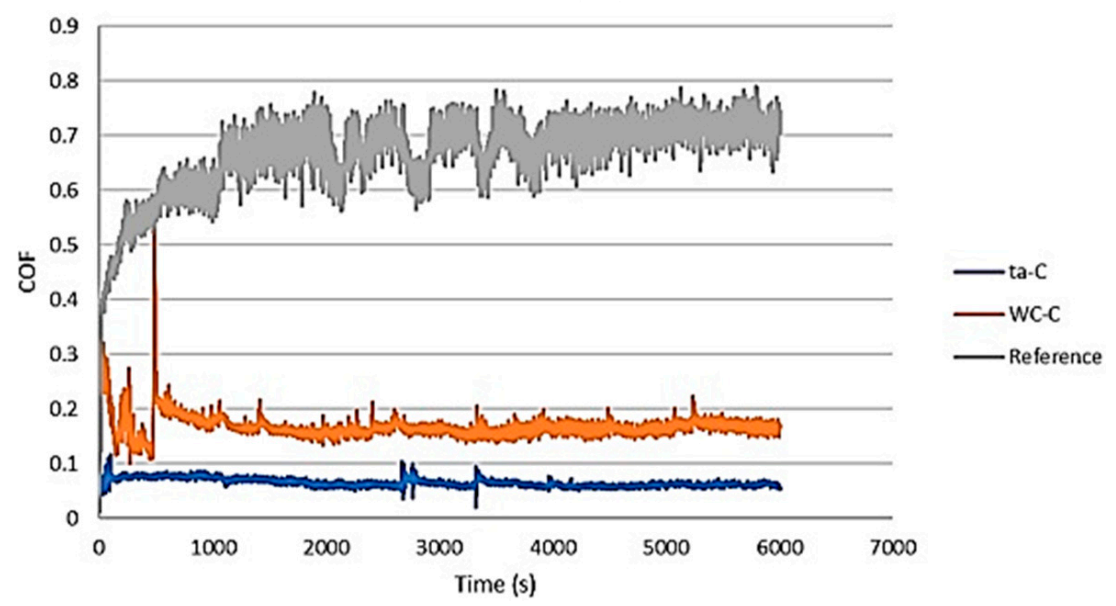

(c)

Figure 8. Friction coefficient of vanadis 4 coated and uncoated samples (a), K360 coated and uncoated samples (b) and vancron coated and uncoated samples (c), respectively. 

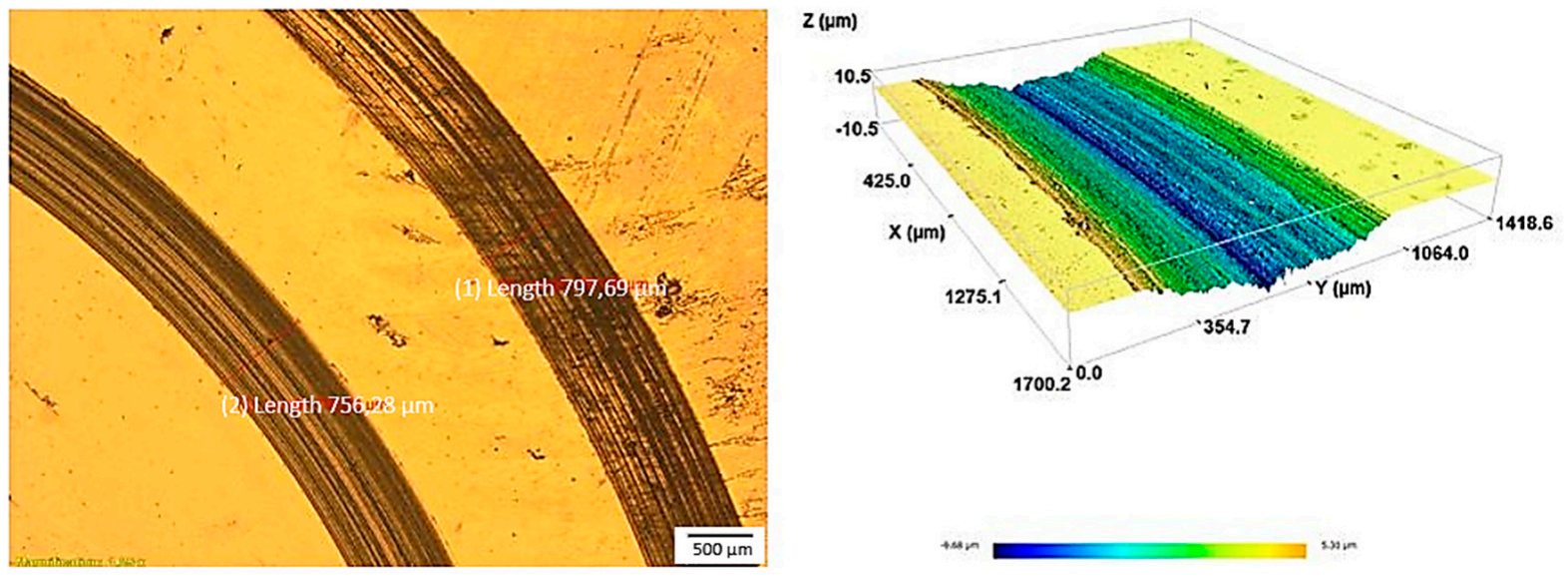

(a)
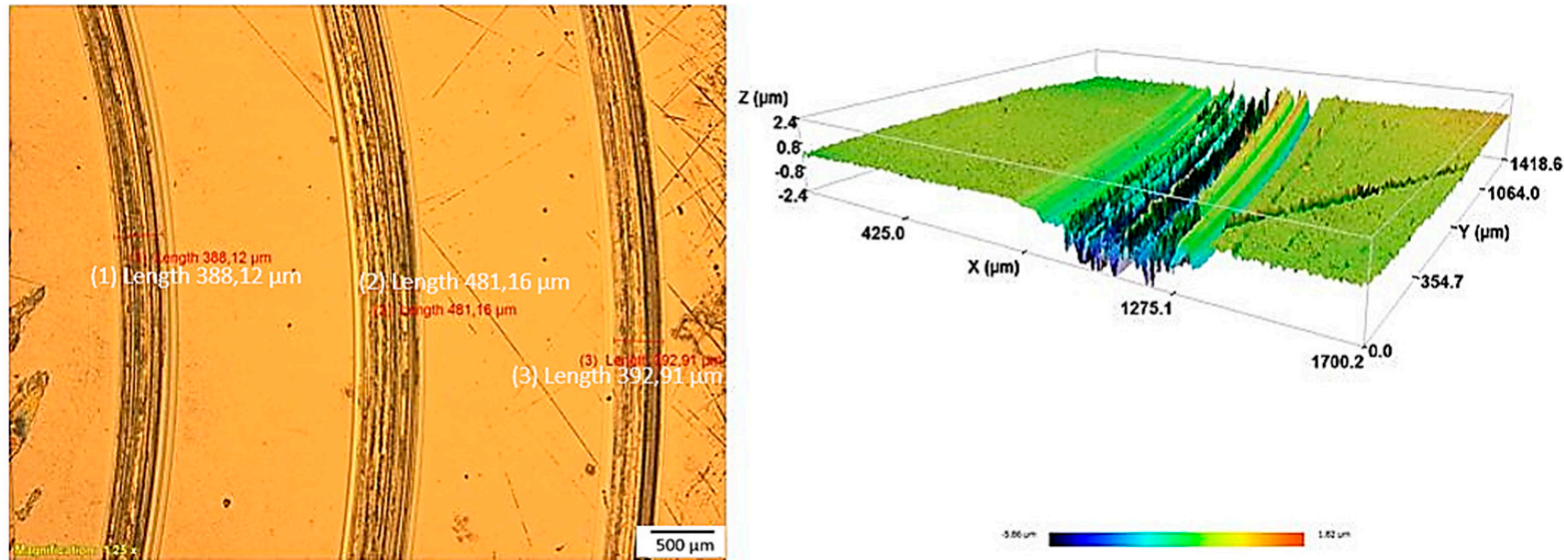

(b)
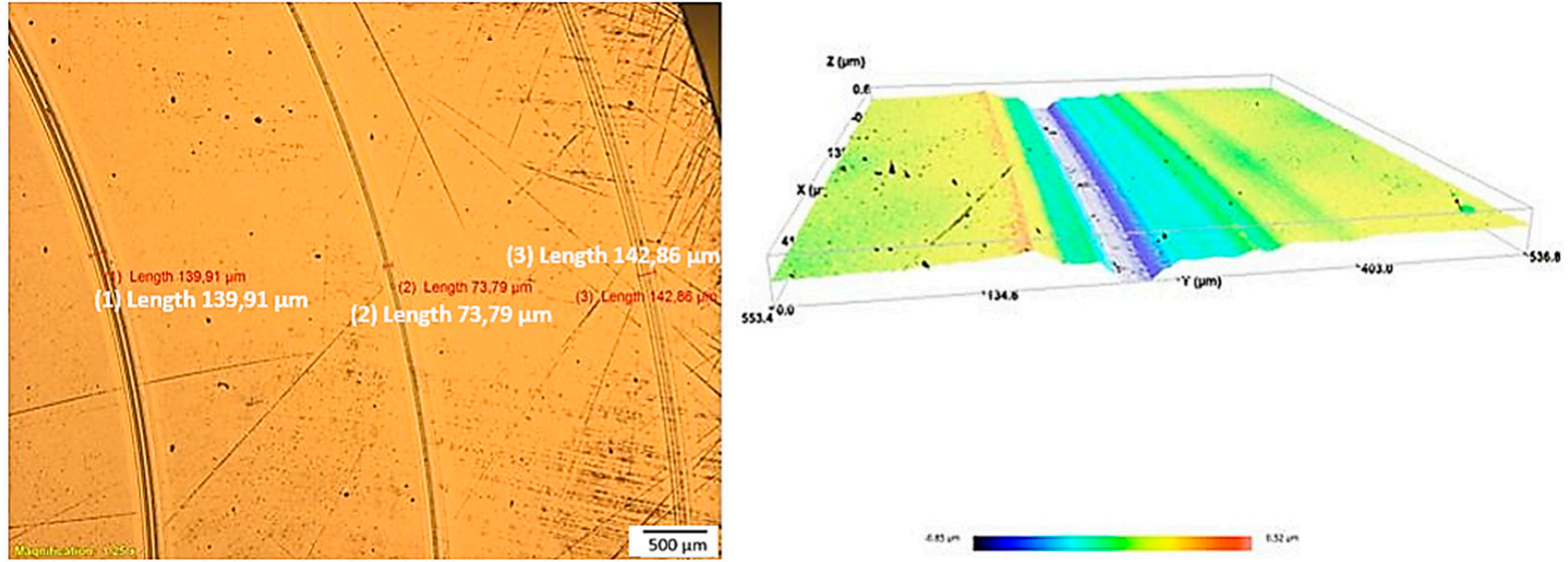

(c)

Figure 9. Example of the aspect of the wear tracks obtained after the friction and wear tests, obtained by optical microscopy (left) and confocal microscopy (right), for the uncoated vanadis 4 sample (a), vanadis 4 with WC:C sample (b) and vanadis 4 with ta-C sample (c). 
Table 6 shows a summary of the results of the friction coefficient and volume loss and wear coefficient calculated with both ASTM G99 and confocal microscopy of each tested sample. The values shown are the average values of the tests carried out with different test radii; the test parameters are the same for all of them. The results obtained by both methods show a similar trend, but there is a difference of one order of magnitude between them. This difference is due to the fact that the calculation carried out following the ASTM G99 standard assumes that the shape of the wear track is that of a perfect sphere, while by confocal measures the real shape of the wear track is taken. The results obtained in both cases show that the highest values of volume loss and wear coefficients were achieved for the uncoated specimens and the smallest for those coated with ta-C. Following the ASTM G99 standard, values of wear coefficient of around $1.7 \times 10^{-5} \mathrm{~mm}^{3} / \mathrm{Nm}$ were obtained for the vancron and vanadis 4 uncoated samples, while the K360 sample presented a worse wear resistance with a coefficient of $4.87 \times 10^{-4} \mathrm{~mm}^{3} / \mathrm{Nm}$. The same trend was observed in the case of results obtained by confocal measures, with values of the order of $10^{-6} \mathrm{~mm}^{3} / \mathrm{Nm}$ for the specimens of vancron and vanadis 4 and of $10^{-5} \mathrm{~mm}^{3} / \mathrm{Nm}$ for that of K360. DLC coated samples showed values up to two orders of magnitude lower in comparison to the reference substrates. Values of about $2.3 \times 10^{-6} \mathrm{~mm}^{3} / \mathrm{Nm}$ were obtained for the WC:C coatings measured following the ASTM G99 and between $4.98 \times 10^{-7}$ and $7.44 \times 10^{-7} \mathrm{~mm}^{3} / \mathrm{Nm}$ for the confocal measures. As previously mentioned, the best wear resistance was presented by the ta-C coatings, with wear coefficients of $3.51 \times 10^{-7} \mathrm{~mm}^{3} / \mathrm{Nm}$ (vancron), $5.29 \times 10^{-7} \mathrm{~mm}^{3} / \mathrm{Nm}(\mathrm{K} 360)$ and $7.17 \times 10^{-8} \mathrm{~mm}^{3} / \mathrm{Nm}$ (vanadis 4) for the ASTM G99 measures, and $7.59 \times 10^{-8} \mathrm{~mm}^{3} / \mathrm{Nm}$ (vancron), $5.37 \times 10^{-8} \mathrm{~mm}^{3} / \mathrm{Nm}$ (vanadis 4 ) and $6.72 \times 10^{-8} \mathrm{~mm}^{3} / \mathrm{Nm}$ (K360) for the confocal measures. The wear coefficient results obtained for the WC:C coating are similar to those reported in reference [72], with values of $1.11 \times 10^{-6} \mathrm{~mm}^{3} / \mathrm{Nm}$ for the N-DLC coating or $1.88 \times 10^{-6} \mathrm{~mm}^{3} / \mathrm{Nm}$ for the DLC sample, or reference [54], showing values of $2.1 \times 10^{-6} \mathrm{~mm}^{3} / \mathrm{Nm}$. As mentioned above, the ta-C coating showed better wear resistance than the WC:C coating, and similar results were reported by García et al. [34] (order of magnitude of $10^{-8} \mathrm{~mm}^{3} / \mathrm{Nm}$ ), by Sun et al. [55] $\left(6.37 \times 10^{-8} \mathrm{~mm}^{3} / \mathrm{Nm}\right)$ and by Kasirowski et al. [26] $\left(6.52 \times 10^{-8} \mathrm{~mm}^{3} / \mathrm{Nm}\right.$ non-nitrided substrate and $4.79 \times 10^{-8} \mathrm{~mm}^{3} / \mathrm{Nm}$ nitrided sample).

Table 6. Summary of the experimental data of friction coefficient, volume loss and wear coefficient measured by ASTM G99 and confocal for reference substrates, ta-C coatings and WC:C coatings.

\begin{tabular}{|c|c|c|c|c|c|}
\hline Sample & $\begin{array}{l}\text { Friction } \\
\text { Coefficient }\end{array}$ & $\begin{array}{c}\text { Volume Loss }\left(\mathrm{m}^{3}\right) \\
\text { ASTM G99 }\end{array}$ & $\begin{array}{l}\text { Volume Loss } \\
\text { Confocal }\left(\mathrm{m}^{3}\right)\end{array}$ & $\begin{array}{c}\text { Wear Coefficient } \\
\text { ASTM G99 }\left(\mathrm{mm}^{3} / \mathrm{Nm}\right)\end{array}$ & $\begin{array}{c}\text { Wear Coefficient } \\
\text { Confocal }\left(\mathrm{mm}^{3} / \mathrm{Nm}\right)\end{array}$ \\
\hline Uncoated vancron & 0.67 & $(9.64 \pm 10) \times 10^{-10}$ & $(2.67 \pm 2.7) \times 10^{-10}$ & $(1.73 \pm 1.69) \times 10^{-5}$ & $(4.88 \pm 4.1) \times 10^{-6}$ \\
\hline Uncoated vanadis 4 & 0.71 & $(7.73 \pm 1.5) \times 10^{-10}$ & $(1.64 \pm 0.48) \times 10^{-10}$ & $(1.70 \pm 0.06) \times 10^{-5}$ & $(3.62 \pm 0.47) \times 10^{-6}$ \\
\hline Uncoated K360 & 0.76 & $(1.21 \pm 1.05) \times 10^{-8}$ & $(4.64 \pm 6.1) \times 10^{-10}$ & $(4.87 \pm 0.77) \times 10^{-4}$ & $(1.31 \pm 0.54) \times 10^{-5}$ \\
\hline Vancron WC:C & 0.097 & $(1.08 \pm 0.38) \times 10^{-10}$ & $(2.43 \pm 0.1) \times 10^{-11}$ & $(2.30 \pm 1.28) \times 10^{-6}$ & $(4.98 \pm 1.04) \times 10^{-7}$ \\
\hline Vanadis $4 \mathrm{WC}: \mathrm{C}$ & 0.15 & $(1.16 \pm 0.41) \times 10^{-10}$ & $(3.44 \pm 1.08) \times 10^{-11}$ & $(2.35 \pm 0.84) \times 10^{-6}$ & $(6.79 \pm 1.51) \times 10^{-7}$ \\
\hline K360 WC:C & 0.112 & $(1.12 \pm 0.24) \times 10^{-10}$ & $(3.65 \pm 0.73) \times 10^{-11}$ & $(2.24 \pm 0.34) \times 10^{-6}$ & $(7.44 \pm 1.89) \times 10^{-7}$ \\
\hline Vancron ta-C & 0.067 & $(1.74 \pm 0.67) \times 10^{-11}$ & $(3.85 \pm 1.14) \times 10^{-12}$ & $(3.51 \pm 1.33) \times 10^{-7}$ & $(7.59 \pm 1.34) \times 10^{-8}$ \\
\hline Vanadis 4 ta-C & 0.07 & $(3.60 \pm 2.93) \times 10^{-12}$ & $(2.66 \pm 0.29) \times 10^{-12}$ & $(7.17 \pm 5.5) \times 10^{-8}$ & $(5.37 \pm 0.53) \times 10^{-8}$ \\
\hline K360 ta-C & 0.105 & $(2.65 \pm 0.73) \times 10^{-11}$ & $(3.43 \pm 1.05) \times 10^{-12}$ & $(5.29 \pm 1.1) \times 10^{-7}$ & $(6.72 \pm 0.72) \times 10^{-8}$ \\
\hline
\end{tabular}

Figures 10 and 11 present a comparative graph of the values related to wear coefficient calculated by ASTM G99 (orange bars) and confocal measures (blue bars), showing good repeatability of the tribological tests. A difference of about an order of magnitude between the two methods is evident in these figures. 


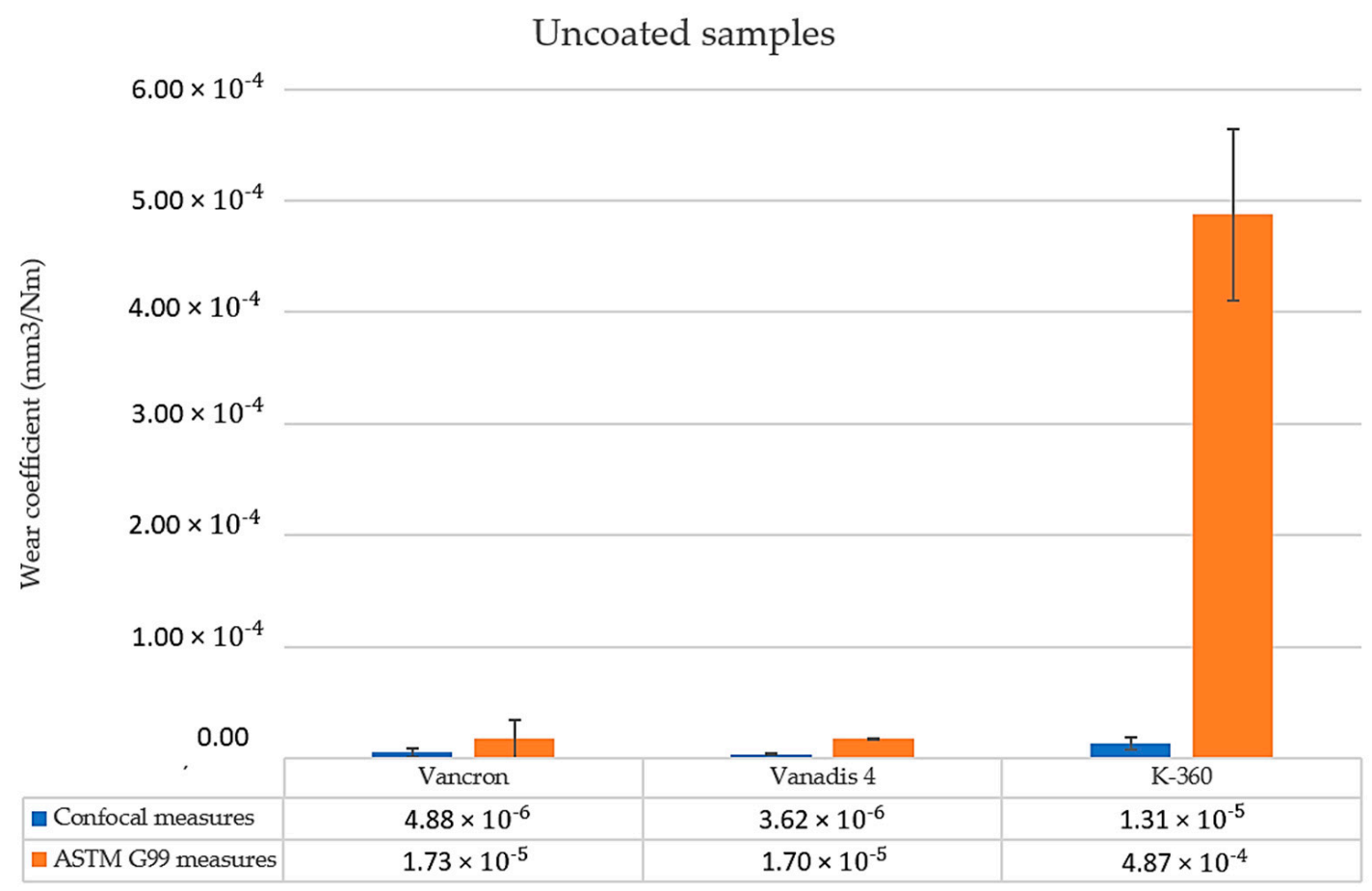

Figure 10. Comparative graph of the values related to wear coefficient calculated by both methods for the uncoated samples.

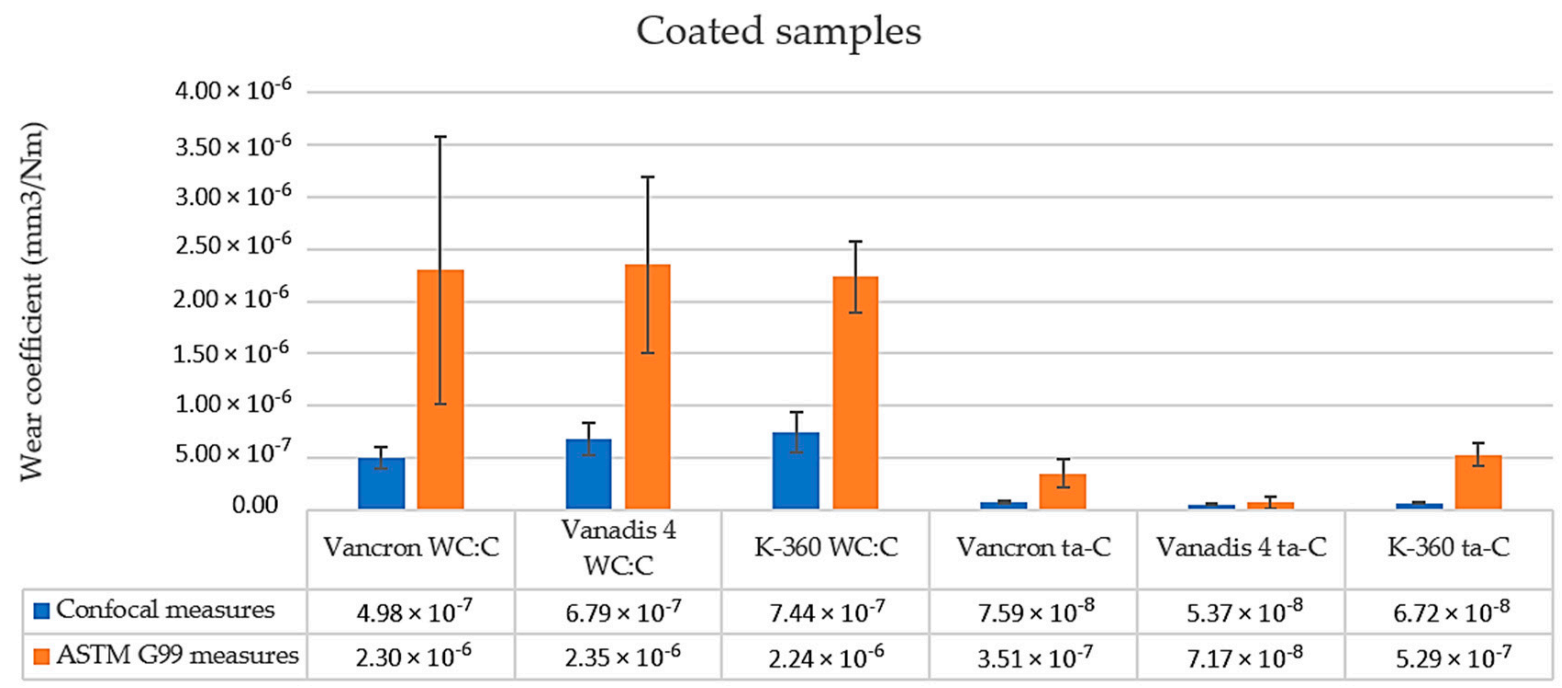

Figure 11. Comparative graph of the values related to wear coefficient calculated by both methods for the ta- $\mathrm{C}$ and WC:C coated samples.

\section{Discussion}

Once all the tests on the samples coated with different DLCs by HiPIMS with positive pulses have been carried out, it is possible to highlight some of their aspects. First of all, Raman spectroscopy showed how the specimens coated with ta-C show a greater number of $\mathrm{sp}^{3}$ hybrid bonds than those of WC:C. This is consistent with the values obtained in the nanohardness tests and shows the importance of the $\mathrm{sp}^{2} / \mathrm{sp}^{3}$ ratio to determine the hardness. The nanohardness values obtained coincide with those shown in previous studies, with higher values of hardness for the ta-C samples than for the WC: $\mathrm{C}$ ones.

It should also be noted that by doping the coating with $\mathrm{W}(\mathrm{WC}: \mathrm{C})$ it is possible to increase its adhesion properties due to the decrease in the surface energy. This is demonstrated by the results of Lc2 and Lc3, where the coating of WC:C presents values 
of around 59 and $75 \mathrm{~N}$, respectively, while for the ta-C coating values of about $25 \mathrm{~N}$ for Lc2 and $50 \mathrm{~N}$ for Lc3 are reported. In this aspect, $\mathrm{k} 360$ steel exhibits a worse performance than the other two since the first adhesive failure appears at a critical load of $32.9 \mathrm{~N}$, which is considerably lower than in the others. The efficacy of the novel HiPIMS with positive pulses technique is also demonstrated, with a clear improvement in the adhesion of the coatings to the substrates.

The resistance to plastic deformation $\left(\mathrm{H}^{3} / \mathrm{E}^{2}\right)$ showed lower values than those found in the literature; specifically, values of around 0.15 were obtained for the ta-C coating and 0.04 for the WC:C coating. However, these values show concordance with those obtained for wear resistance since the higher the value of $\mathrm{H}^{3} / \mathrm{E}^{2}$, the better the resistance to wear of the coatings. The wear coefficient values show how for ta- $\mathrm{C}$ values of the order of $10^{-8} \mathrm{~mm}^{3} / \mathrm{Nm}$ were obtained; on the other hand, for WC:C, values of the order of $10^{-7} \mathrm{~mm}^{3} / \mathrm{Nm}$ were obtained (measured by the confocal microscope). As already stated, the effect of doping the coating with W (WC:C) is also evident in these results. The addition of $\mathrm{W}$ to the DLC structure allows the reduction of the compressive residual stress, enhancing adhesion critical load values, but also affects the hardness and wear resistance of the coatings, showing lower values of hardness and wear resistance. The COF values of the WC: $\mathrm{C}$ coatings are higher than the ta- $\mathrm{C}$ ones, and they show higher friction during the run-in period due to the formation of oxide phases.

Comparing the results obtained for the different substrates, it can be said that powder metallurgical steels show better properties than the ESR steel. This statement is demonstrated with the adhesion results (Lc2 for WC:C) and the values obtained for the wear resistance.

Finally, it should be noted that the slight discrepancies (about an order of magnitude) showed in the wear rate measurements with both different methods-following the ASTM G99 standard and the confocal directly - can be associated with the fact that the wear tracks do not have perfect spherical shapes due to the small wear suffered by the alumina balls during the pin-on-disc tests. This could lead to the values obtained by confocal measures being lower but more realistic.

\section{Conclusions}

In this work, high quality tools steels have been coated with advanced DLC coatings by using the novel HiPIMS technique with positive pulses. The objective of this work was to find the best results for the most extreme and demanding applications, and for this type of application, steels such as those that have been studied are commonly used. With this technique, tribological properties of great interest were obtained, such as a great resistance to wear or resistance to plastic deformation, in addition to improving the adhesion of the coating with the substrate. After analyzing the experimental procedure that was carried out and the results obtained, some aspects can be highlighted:

- Raman spectroscopy showed that ta-C coatings have a higher number of $\mathrm{sp}^{3}$ bonds, which is consistent with these coatings being harder than those of WC:C;

- The nanohardness of coatings was around $25 \mathrm{Gpa}$ for the ta-C and around $14 \mathrm{GPa}$ for the WC:C coating;

- The relationship between resistance to plastic deformation and resistance to wear was proven, since the higher values of $\mathrm{H}^{3} / \mathrm{E}^{2}$ correlated with higher values of resistance to wear. It should be noted that this is a sign that hardness is not the only parameter that determines the wear behavior of coatings;

- The coefficient of friction (COF) against alumina was considerably lower than that of the substrate (0.7) in the case of both coatings in all materials, obtaining values of around 0.07 for the ta-C coating and 0.1 for the WC:C coating;

- The coatings showed very good adhesion to the substrate. The coatings of WC:C presented better results than those of ta-C, reaching values greater than $70 \mathrm{~N}$ for the critical load $\mathrm{L}_{\mathrm{C}} 3$. Vanadis 4 and vancron presented better adhesion than $\mathrm{K} 360$, as shown by the Lc2 values obtained for the WC:C coating; 
- The two coatings improve the wear resistance of the substrate, as demonstrated by the values obtained for volume loss and wear coefficient, especially for the case of ta-C. The WC:C coatings showed wear coefficient values one order of magnitude lower than the substrate $\left(10^{-7}\right)$, while in the case of ta- $C$ values, values two orders of magnitude lower than the substrate were achieved $\left(10^{-8}\right)$.

The experimental results show that these DLC coatings obtained by the novel HiPIMS technique with positive pulses are a great option for implementation at an industrial level and are capable of competing with other types of coatings with which they could not do so until now.

If the results obtained for the different substrates are compared, it can be seen that the adhesion of powder metallurgical steels is greater than the ESR steels, while the first adhesive failure (Lc2) appears later with the WC:C coating in the case of the these steels (32.9 $\mathrm{N}$ for $\mathrm{K} 360$ and near $59 \mathrm{~N}$ for the powder metallurgical steels). A better trend in the results obtained for the wear coefficient for these steels can be observed, as shown in the comparative graphs. This better behavior could be due to their higher quality, which is characterized by a better dimensional stability, greater homogeneity of carbides and greater mechanical properties such as toughness or yield strength. Although further studies are necessary to determine the cause of this better behavior, these properties could lead into lower and more homogeneous residual stress in the substrate, resulting in lower strain on the interface substrate coating, and a greater ability to withstand the loads transmitted through the coating. A greater chemical compatibility seems to be another factor that affects the adhesion between the coating and the substrate and the higher content in vanadium in powder metallurgical steels could increase the yield strength of the steel, which could explain the better behavior against loads.

Author Contributions: Conceptualization, J.A.G., A.C., J.A.S., I.F., J.F.P., and E.B.; formal analysis, J.A.G. and A.C.; investigation, A.C., J.A.G., E.J.-P., E.A., J.F.P., J.F.d.A., and J.A.S.; resources, E.B.; writing-original draft preparation, A.C. and J.A.G.; writing—review and editing, A.C., J.A.G., E.J.-P., J.F.P., J.F.d.A., and J.A.S.; supervision, J.A.G.; project administration, J.A.G.; funding acquisition, E.J.-P. and J.A.G. All authors have read and agreed to the published version of the manuscript.

Funding: Funded in part by the Spanish Ministry of Science, Innovation and Universities through grant PGC2018-096855-B-C41, PGC2018-096855-B-C43 and PGC2018-096855-A-C44.

Data Availability Statement: Data is contained within the article.

Acknowledgments: AIN acknowledges the support of CDTI Ministerio de Ciencia e Innovación of Spain through the project CERVERA (CER2019-1003).

Conflicts of Interest: The authors declare no conflict of interest.

\section{References}

1. Donnet, C.; Erdemir, A. New horizon in the tribology of diamondlike carbon films. Surf. Eng. 2008, 24, 399-401. [CrossRef]

2. Erdemir, A.; Donnet, C. Tribology of diamond-like carbon films: Recent progress and future prospects. J. Phys. D Appl. Phys. 2006, 39. [CrossRef]

3. Pierson, H.O. Handbook of Carbon, Graphite, Diamond and Fullerenes: Properties, Processing and Applications; Noyes Publication: Park Ridge, NJ, USA, 1993.

4. Robertson, J. Diamond-like amorphous carbon. Mater. Sci. Eng. R 2002, 37, 129-281. [CrossRef]

5. Bewilogua, K.; Hofmann, D. History of diamond-like carbon films-From first experiments to worldwide applications. Surf. Coat. Technol. 2014, 242, 214-225. [CrossRef]

6. Bull, S.J. Tribology of carbon coatings: DLC, diamond and beyond. Diam. Relat. Mater. 1995, 4, 827-836. [CrossRef]

7. Saxena, P.; Schinzel, M.; Andrich, M.; Modler, N. Development of a novel test-setup for identifying the frictional characteristics of carbon fibre reinforced polymer composites at high surface pressure. Mater. Sci. Eng. 2016, 149, 012124. [CrossRef]

8. Rodríguez, R.J.; García, J.A.; Martinez, R.; Lerga, B.; Rico, M.; Fuentes, G.G.; Guette, A.; Labruguere, C.; Lahaye, M. Tribological metal-carbon coatings deposited by PVD magnetron sputtering. Appl. Surf. Sci. 2004, 235, 53-59. [CrossRef]

9. Dai, M.; Zhou, K.; Yuan, Z.; Ding, Q.; Fu, Z. The cutting performance of diamond and DLC-coated cutting tools. Diam. Relat. Mater. 2000, 9, 1753-1757. [CrossRef]

10. Fukui, H.; Okida, J.; Omori, N.; Moriguchi, H.; Tsuda, K. Cutting performance of DLC coated tools in dry machining aluminum alloys. Surf. Coat. Technol. 2004, 187, 70-76. [CrossRef] 
11. Silva, F.; Martinho, R.P.; Alexandre, R.; Baptista, A. Increasing the wear resistance of molds for injection of glass fiber reinforced plastics. Wear 2011, 271, 2494-2499. [CrossRef]

12. Hauert, R.; Thorwarth, K.; Thorwarth, G. An overview on diamond-like carbon coatings in medical applications. Surf. Coat. Technol. 2013, 233, 119-130. [CrossRef]

13. Treutler, C.P.O. Industrial use of plasma-deposited coatings for components of automotive fuel injection systems. Surf. Coat. Technol. 2005, 200, 1969-1975. [CrossRef]

14. Novikov, N.V.; Gontar, A.G.; Khandozhko, S.I.; Kutsay, A.M.; Tkach, V.N.; Gorokhov, V.Y.; Belitsky, G.M.; Vasinc, A.V. Protective diamond-like coatings for optical materials and electronic devices. Diam. Relat. Mater. 2000, 9, 792-795. [CrossRef]

15. Morshed, M.M.; McNamara, B.P.; Cameron, D.C.; Hashmi, M.S.J. Stress and adhesion in DLC coatings on 316L stainless steel deposited by a neutral beam source. J. Mater. Process. Technol. 2003, 141, 127-131. [CrossRef]

16. Mosaner, P.; Bonelli, M.; Miotello, A. Pulsed laser deposition of diamond-like carbon films: Reducing internal stress by thermal annealing. Appl. Surf. Sci. 2003, 208-209, 561-565. [CrossRef]

17. Neuville, S.; Matthews, A. A perspective on the optimisation of hard carbon and related coatings for engineering applications. Thin Solid Films 2007, 515, 6619-6653. [CrossRef]

18. Silva, S.R.P. (Ed.) Properties of Amorphous Carbon; The Institution of Engineering and Technology: London, UK, 2008 ; pp. 311-312.

19. McWilliams, A. Diamond, Diamond-Like and CBN Films \& Coating Products. BCC Res. 2010, 7, 160.

20. Ghiotti, A.; Bruschi, S. Tribological behaviour of DLC coatings for sheet metal forming tools. Wear 2011, 271, 2454-2458. [CrossRef]

21. Sgarabotto, F.; Ghiotti, A.; Bruschi, S. Novel experimental set-up to investigate the wear of coatings for sheet metal forming tools. Key Eng. Mater. 2013, 554-557, 825-832. [CrossRef]

22. Helmersson, U.; Lattemann, M.; Bohlmark, J.; Ehiasarian, A.; Gudmundsson, J.T. Ionized physical vapor deposition (IPVD): A review of technology and applications. Thin Solid Films 2006, 513, 1-24. [CrossRef]

23. Santiago, J.; Fernández-Martínez, I.; Kozák, T.; Capek, J.; Wennberg, A.; Molina-Aldareguia, J.; Bellido-González, V.; GonzálezArrabal, R.; Monclús, M.A. The influence of positive pulses on HiPIMS deposition of hard DLC coatings. Surf. Coat. Technol. 2019, 358, 43-49. [CrossRef]

24. Bhushan, B. Modern Tribology Handbook; Boca Raton (Fla.); CRC Press: Boca Raton, FL, USA, 2001; pp. $102-136$.

25. Wang, Q.J.; Chung, Y.-W. Encyclopedia of Tribology; Springer US: Boston, MA, USA, 2013; pp. 794-800.

26. Kasiorowski, T.; Lin, J.; Soares, P.; Lepienski, C.M.; Neitzke, C.A.; de Souza, G.B.; Torres, R.D. Microstructural and tribological characterization of DLC coatings deposited by plasma enhanced techniques on steel substrates. Surf. Coat. Technol. 2019, 389, 125615. [CrossRef]

27. Duminica, F.-D.; Belchi, R.; Libralesso, L.; Mercier, D. Investigation of Cr(N)/DLC multilayer coatings elaborated by PVD for high wear resistance and low friction applications. Surf. Coat. Technol. 2018, 337, 396-403. [CrossRef]

28. Shioga, P.H.T.; Binder, C.; Hammes, G.; Klein, A.N.; de Mello, J.D.B. Effects of Different Plasma Nitrided Layers on the Tribological Performance of DLC Coatings. Mater. Res. 2016, 19, 1180-1188. [CrossRef]

29. Podgornik, B.; Vižintin, J. Influence of substrate treatment on the tribological properties of DLC coatings. Diam. Relat. Mater. 2001, 10, 2232-2237. [CrossRef]

30. Marin, E.; Lanzutti, A.; Nakamura, M.; Zanocco, M.; Zhu, W.; Pezzotti, G.; Andreatt, F. Corrosion and scratch resistance of DLC coatings applied on chromium molybdenum steel. Surf. Coat. Technol. 2019, 378, 124944. [CrossRef]

31. Avelar-Batista, J.C.; Spain, E.; Fuentes, G.G.; Sola, A.; Rodriguez, R.; Housden, J. Triode plasma nitriding and PVD coating: A successful pre-treatment combination to improve the wear resistance of DLC coatings on Ti6Al4V alloy. Surf. Coat. Technol. 2006, 201, 4335-4340. [CrossRef]

32. Liu, L.; Wu, Z.; An, X.; Shao, T.; Xiao, S.; Cui, S.; Lin, H.; Fu, R.K.Y.; Tian, X.; Chu, P.K.; et al. Improved interfacial adhesion between TiAlN/DLC multi-layered coatings by controlling the morphology via bias. Surf. Coat. Technol. 2017, 331, 15-20. [CrossRef]

33. Santiago, J.A.; Fernández-Martínez, I.; Wennberg, A.; Molina-Aldareguia, J.M.; Castillo-Rodríguez, M.; Rojas, T.C.; Sánchez-López, J.C.; González, M.U.; García-Martín, J.M.; Li, H.; et al. Adhesion enhancement of DLC hard coatings by HiPIMS metal ion etching pretreatment. Surf. Coat. Technol. 2018, 349, 787-796. [CrossRef]

34. García, J.A.; Rivero, P.J.; Barba, E.; Fernández, I.; Santiago, J.A.; Palacio, J.F.; Fuente, G.G.; Rodríguez, R.J. A Comparative Study in the Tribological Behavior of DLC Coatings Deposited by HiPIMS Technology with Positive Pulses. Metals 2020, 10, 174. [CrossRef]

35. Tobola, D.; Brostow, W.; Czechowski, K.; Rusek, P. Improvement of wear resistance of some cold working tool steels. Wear 2017, 382-383, 29-39. [CrossRef]

36. Kim, H.; Kang, J.-Y.; Son, D.; Lee, T.-H.; Cho, K.-M. Evolution of carbides in cold-work tool steels. Mater. Charact. 2015, 107, 376-385. [CrossRef]

37. Kanga, J.-Y.; Kima, H.; Sonc, D.; Kimd, C.; Park, S.K.; Lee, T.-H. Hot-worked microstructure and hot workability of cold-work tool steels. Mater. Charact. 2018, 135, 8-17. [CrossRef]

38. Fukaura, K.; Sunada, H.; Yokoyama, Y.; Teramoto, K.; Yokoi, D.; Tsujii, N. Improvement of strength and toughness of SKD11 type cold work tool steel. Tetsu-to-Hagané 1998, 84, 230-235. [CrossRef]

39. Fukaura, K.; Yokoyama, Y.; Yokoi, D.; Tsujii, N.; Ono, K. Fatigue of cold-work tool steel: Effect of heat treatment and carbide morphology on fatigue crack formation, life, and fracture surface observation. Metall. Mater. Trans. A 2004, 35, 1289-1300. [CrossRef] 
40. Arieta, F.; Netto, E.B.M.; Reguly, A.; Pannes, W.K.; Beutler, U.; van Soest, F.; Ernst, C. Impact properties of vacuum heat treated AISI D2 and 8\%Cr-cold work tool steels. J. ASTM Int. 2011, 8, 129-145. [CrossRef]

41. Picas, I.; Cuadrado, N.; Casellas, D.; Goez, A.; Llanes, L. Microstructural effects on the fatigue crack nucleation in cold work tool steels. Proc. Eng. 2010, 2, 1777-1785. [CrossRef]

42. Arslan, F.K.; Altinsoy, I.; Hatman, A.; Ipek, M.; Zeytin, S.; Bindal, C. Characterization of cryogenic heat treated Vanadis 4 PM cold work tool steel. Vacuum 2011, 86, 370-373. [CrossRef]

43. Oppenkowski, A.; Weber, S.; Theisen, W. Evaluation of factors influencing deep cryogenic treatment that affect the properties of tool steels. J. Mater. Process. Technol. 2010, 210, 1949-1955. [CrossRef]

44. Riofano, R.M.M.; Casteletti, L.C.; Canale, L.C.F.; Totten, G.E. Improved wear resistance of P/M tool steel alloy with different vanadium contents after ion nitriding. Wear 2008, 265, 57-64. [CrossRef]

45. Ko, D.-C.; Kim, S.-G.; Kim, B.-M. Influence of microstructure on galling resistance of cold-work tool steels with different chemical compositions when sliding against ultra-high-strength steel sheets under dry condition. Wear 2015, 338-339, 362-371. [CrossRef]

46. Gåård, A.; Krakhmalev, P.; Bergström, J. Wear mechanisms in deep drawing of carbon steel—Correlation to laboratory testing. Lubr. Sci. 2008, 14, 1-9. [CrossRef]

47. Kim, H.; Han, S.; Yan, Q.; Altan, T. Evaluation of tool materials, coatings and lubricants in forming galvanized advanced high strength steels (AHSS). CIRP Ann. Manuf. Technol. 2008, 14, 299-304. [CrossRef]

48. García, J.A.; Rodríguez, R.J.; Martínez, R.; Fernández, C.; Fernández, A.; Payling, R. Depth profiling of industrial surface treatments by rf and dc glow discharge spectrometry. Appl. Surf. Sci. 2004, 235, 97-102. [CrossRef]

49. ASTM G99-17. Standard Test Method for Wear Testing with a Pin-on-Disk Apparatus; American Society for Testing and Materials: West Conshohocken, PA, USA, 2017.

50. Oliver, W.C.; Pharr, G.M. An improved technique for determining hardness and elastic modulus using load and displacement sensing indentation experiments. J. Mater. Res. 1992, 7, 1564-1583. [CrossRef]

51. Bec, S.; Tonck, A.; Loubet, J.L. A simple guide to determine elastic properties of films on substrate from nanoindentation experiments. Philos. Mag. 2006, 86, 5347-5358. [CrossRef]

52. Botero, C.; Jimenez-Pique, E.; Seuba, J.; Kulkarni, T.; Sarin, V.; Llanes, L. Mechanical behavior of $3 \mathrm{Al}_{2} \mathrm{O}_{3} \cdot 2 \mathrm{SiO}_{2}$ films under nanoindentation. Acta Mater. 2012, 60, 5889-5899. [CrossRef]

53. Ferrari, A.C.; Robertson, J. Interpretation of Raman spectra of disordered and amorphous carbon. Phys. Rev. B 2000, 61, 14095-14107. [CrossRef]

54. Czyzniewski, A. Optimising deposition parameters of W-DLC coatings for tool materials of high speed steel and cemented carbide. Vacuum 2012, 86, 2140-2147. [CrossRef]

55. Sun, W.; Li, M.; Wu, M.; Hu, J. Uniformity of Si-containing diamond-like carbon films deposited at different positions by mesh hollow cathode discharge. Results Phys. 2019, 14, 102480. [CrossRef]

56. Leyland, A.; Matthews, A. On the significance of the H/E ratio in wear control: A nanocomposite coating approach to optimised tribological behaviour. Wear 2000, 246, 1-11. [CrossRef]

57. Charitidis, C.A. Nanomechanical and nanotribological properties of carbon-based thin films: A review. Int. J. Refract. Hard Met. 2010, 28, 51-70. [CrossRef]

58. Galvan, D.; Pei, Y.T.; De Hosson, J.T.M. Deformation and failure mechanism of nano-composite coatings under nano-indentation. Surf. Coat. Technol. 2006, 200, 6718-6726. [CrossRef]

59. Lopes, B.B.; Rangel, R.C.C.; Antonio, C.A.; Durrant, S.F.; Cruz, N.C.; Rangel, E.C. Mechanical and Tribological Properties of Plasma Deposited a-C:H:Si:O Films; Nanoindentation in Materials Science IntechOpen: London, UK, 2012; pp. $179-202$.

60. Charitidis, C.; Logothetidis, S.; Douka, P. Nanoindentation and nanoscratching studies of amorphous carbon films. Diam. Relat. Mater. 1999, 8, 558-562. [CrossRef]

61. Le Bourhis, E. Indentation mechanics and its application to thin film characterization. Vacuum 2008, 82, 1353-1359. [CrossRef]

62. Mayrhofer, P.H.; Mitterer, C.; Musil, J. Structure-property relationships in single- and dual-phase nanocrystalline hard coatings. Surf. Coat. Technol. 2003, 174-175, 725-731. [CrossRef]

63. Wang, L.; Li, L.; Kuang, X. Effect of substrate bias on microstructure and mechanical properties of WCDLC coatings deposited by HiPIMS. Surf. Coat. Technol. 2018, 352, 33-41. [CrossRef]

64. Luo, H.; Sun, H.; Gao, F.; Billard, A. Mechanical properties, thermal stability and oxidation resistance of HfC/a-C:H films deposited by HiPIMS. J. Alloys Compd. 2020, 847, 156538. [CrossRef]

65. Sánchez-López, J.C.; Fernández, A. Doping and Alloying Effects on DLC Coatings. In Tribology of Diamond-Like Carbon Films; Donnet, C., Erdemir, A., Eds.; Springer: Boston, MA, USA, 2008; pp. 311-338.

66. Moreno-Bárcenas, A.; Alvarado-Orozco, J.M.; Carmona, J.M.G.; Mondragón-Rodríguez, G.C.; González-Hernández, J.; GarcíaGarcía, A. Synergistic effect of plasma nitriding and bias voltage on the adhesion of diamond-like carbon coatings on M2 steel by PECVD. Surf. Coat. Technol. 2019, 374, 327-337. [CrossRef]

67. Cao, L.; Liu, J.; Wan, Y.; Pu, J. Corrosion and tribocorrosion behavior of W doped DLC coating in artificial seawater. Diam. Relat. Mater. 2020, 109, 108019. [CrossRef]

68. Voevodin, A.A.; O'Neill, J.P.; Zabinski, J.S. Tribological performance and tribochemistry of nanocrystalline WC/amorphous diamond-like carbon composites. Thin Solid Films 1999, 342, 194-200. [CrossRef] 
69. Wang, L.; Lin, J.; Zhu, C.; Li, G.; Kuang, X.; Huang, K. Effects of HiPIMS pulse-length on plasma discharge and on the properties of WC-DLC coatings. Appl. Surf. Sci. 2019, 487, 526-538. [CrossRef]

70. Tillman, W.; Lopes Dias, N.; Stangier, D. Influence of plasma nitriding pretreatments on the tribo-mechanical properties of DLC coatings sputtered on AISI H11. Surf. Coat. Technol. 2019, 357, 1027-1036. [CrossRef]

71. Makówka, M.; Pawlak, W.; Konarski, P.; Wendler, B.; Szymanowski, H. Modification of magnetron sputter deposition of nc-WC/a-C(:H) coatings with an additional RF discharge. Diam. Relat. Mater. 2019, 98, 107509. [CrossRef]

72. Bouzakis, K.-D.; Vidakis, N.; Michailidis, N.; Leyendecker, T.; Erkens, G.; Fuss, G. Quantification of properties modification and cutting performance of $\left(\mathrm{Ti}_{1-x} \mathrm{Al}_{x}\right) \mathrm{N}$ coatings at elevated temperatures. Surf. Coat. Technol. 1999, 120-121, 34-43. [CrossRef] 